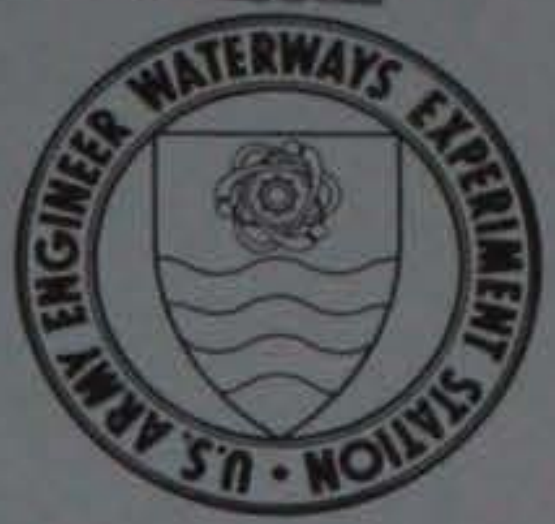

TECHNICAL REPORT SL-82-8

\title{
SEISMIC ANALYSIS OF INTAKE TOWERS
}

by

\author{
Paul F. Mlakar, Patricia S. Jones
}

Structures Laboratory

U. S. Army Engineer Waterways Experiment Station

P. O. Box 631, Vicksburg, Miss. 39180

October 1982

Final Report

Approved For Public Release; Distribution Unlimited

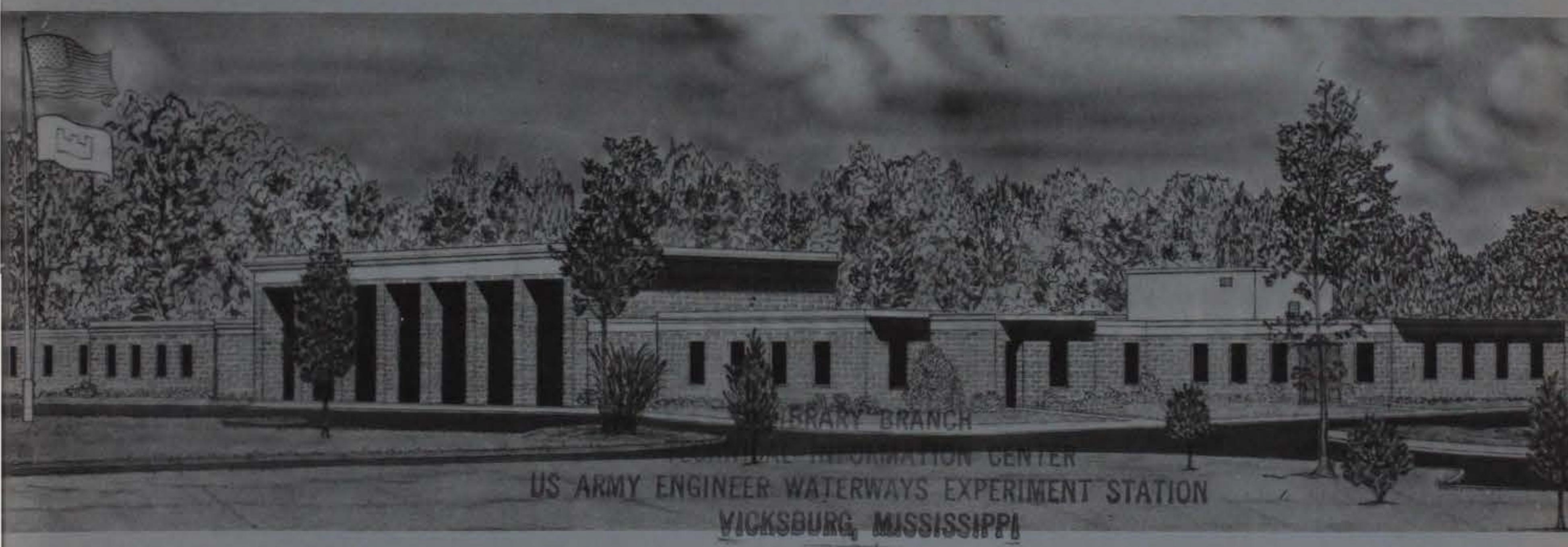

Prepared for Office, Chief of Engineers, U. S. Army Washington, D. C. 20314 


\begin{tabular}{|c|c|}
\hline REPORT DOCUMENTATION PAGE & $\begin{array}{l}\text { READ INSTRUCTIONS } \\
\text { BEFORE COMPLETING FORM } \\
\end{array}$ \\
\hline $\begin{array}{l}\text { 1. REPORT NUMBER } \\
\text { Technica1 Report SL-82-8 }\end{array}$ & 3. RECIPIENT'S CATALOG NUMBER \\
\hline \multirow[t]{2}{*}{$\begin{array}{l}\text { 4. TITLE (and Subtite) } \\
\text { SEISMIC ANALYSIS OF INTAKE TOWERS }\end{array}$} & $\begin{array}{l}\text { 5. TYPE OF REPORT \& PERIOD COVERED } \\
\text { Final report }\end{array}$ \\
\hline & 6. PERFORMING ORG. REPORT NUMBER \\
\hline $\begin{array}{l}\text { 7. AUTHOR(o) } \\
\text { Paul F. Mlakar } \\
\text { Patricia S. Jones }\end{array}$ & 8. CONTRACT OR GRANT NUMBER(B) \\
\hline $\begin{array}{l}\text { 9. PERFORMING ORGANIZATION NAME AND ADDRESS } \\
\text { U. S. Army Engineer Waterways Experiment Station } \\
\text { Structures Laboratory } \\
\text { P. O. Box } 631 \text {, Vicksburg, Miss. } 39180\end{array}$ & $\begin{array}{l}\text { 10. PROGRAM ELEMENT, PROJECT, TASK } \\
\text { AREA Q WORK UNIT NUMBERS } \\
\text { Structural Engineering } \\
\text { Research Work Unit } 31588\end{array}$ \\
\hline \multirow{2}{*}{$\begin{array}{l}\text { 11. CONTROLLING OFFICE NAME AND ADDRESS } \\
\text { Office, Chief of Engineers, U. S. Army } \\
\text { Washington, D. C. } 20314\end{array}$} & $\begin{array}{l}\text { 12. REPORT DATE } \\
\text { OC tober } 1982\end{array}$ \\
\hline & $\begin{array}{l}\text { 13. NUMBER OF PAGES } \\
56\end{array}$ \\
\hline \multirow[t]{2}{*}{ 14. MONITORING AGENCY NAME \& ADDRESS(If difforent from Controllind Office) } & $\begin{array}{l}\text { 15. SECURITY CLASS. (of thlo roport) } \\
\text { Unclassified }\end{array}$ \\
\hline & $\begin{array}{l}\text { 15a. DECLASSIFICATION/DOWNGRADING } \\
\text { SCHEDULLE }\end{array}$ \\
\hline
\end{tabular}

Approved for public release; distribution unlimited.

17. DISTRIBUTION STATEMENT (of the abstract ontered in Block 20, if difforent from Report)

18. SUPPLEMENTARY NOTES

Available from National Technical Information Service, 5285 Port Royal Road, Springfield, Va. 22151.

19. KEY WORDS (Continue on reverse side if necessery and identily by block number)

Earthquake prediction

Earthquake resistant structures

Intakes

Seismic risks

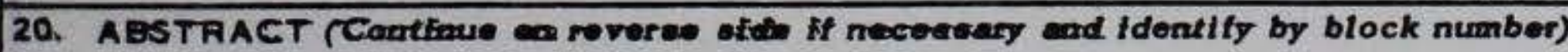

This report discusses practical analytical methods for evaluating the seismic safety of intake towers. Methods of various degrees of sophistication and conservatism are examined which approximately consider linear structural dynamic behavior and site-specific earthquake motion. The need for further research to incorporate other considerations is explained. 


\section{Preface}

This study was conducted between January and June 1981 by personnel of the U. S. Army Engineer Waterways Experiment Station (WES) under the sponsorship of the Directorate of Civil Works of the Office, Chief of Engineers, U. S. Army. The work was funded under the Structural Engineering Research Work Unit 31588.

The work was conducted under the supervision of Messrs. Bryant Mather, Chief, Structures Laboratory (SL), William J. Flathau, Assistant Chief, SL, and James T. Ballard, Chief, Structural Mechanics Division, SL. This report was written by Dr. Paul F. Mlakar and Ms. Patricia S. Jones. During its preparation, numerous helpful discussions were held among the authors, CPT Robert D. Volz, and Messrs. C. Dean Norman, Vincent P. Chiarito, and Ken P. Vitaya-Udom.

Commander and Director of WES during the preparation and publication of this report was COL Tilford C. Creel, CE. Mr. F. R. Brown was Technical Director. 
Preface . . . . . . . . . . . . . . . . . . . . 1

Conversion Factors, Non-SI to SI (Metric) Units of Measurement. . 3 Introduction . . . . . . . . . . . . . . . . . 4

Seismic Coefficient Method ................. 4

Design Earthquake ...................... 5

Axisymmetric Analyses... . . . . . . . . . . . . . . 8

Analysis with Program EATSW . . . . . . . . . . . . 8

Two-mode added mass analysis . . . . . . . . . . . . 15

Montes-Rosenblueth analysis . . . . . . . . . . . 20

Sequence of analyses .. . . . . . . . . . . . 22

Practical Treatment of Asymmetry, Foundation, and Embedment . . . 23

Criteria . . . . . . . . . . . . . . . . . . 24

Additional Research Needed . . . . . . . . . . . . . 25

Summary . . . . . . . . . . . . . . . . . . 26

References ........................ . 27

Appendix A: Two-Mode Added Mass Approximate Analysis

of the San Bernardino Tower Excited by the

Taft, Calif., Earthquake, 21 July 1952

(S69E Component) . . . . . . . . . . . . A1

Appendix B: Montes-Rosenblueth Approximate Analysis

of the San Bernardino Tower Excited by the

Taft, Calif., Earthquake, 21 July 1952

(S69E Component) . . . . . . . . . . . . . B 


\section{Conversion Factors, Non-SI to SI (Metric) \\ Units of Measurement}

Non-SI units of measurement used in this report can be converted to SI (metric) units as follows:

\begin{tabular}{|c|c|c|}
\hline Multiply & By & To Obtain \\
\hline feet & 0.3048 & metres \\
\hline inches & 0.0254 & metres \\
\hline inches per second squared & 0.0254 & metres per second squared \\
\hline inch-kips (force) & 112.9848 & newton-metres \\
\hline inch-pounds (force) & 0.1129848 & newton-metres \\
\hline kips (1000 1b force) & 4448.222 & newtons \\
\hline $\begin{array}{l}\text { pound (force)-feet } \\
\text { squared }\end{array}$ & 0.413253 & newton-metres squared \\
\hline $\begin{array}{l}\text { pound (force)-inches } \\
\text { squared }\end{array}$ & 0.028698 & newton-metres squared \\
\hline pounds (force) & 4.448222 & newtons \\
\hline $\begin{array}{l}\text { pound (force)-seconds } \\
\text { squared per inch }\end{array}$ & 175.1268 & $\begin{array}{l}\text { newton-seconds squared } \\
\text { per metre }\end{array}$ \\
\hline $\begin{array}{l}\text { pound (force)-seconds } \\
\text { squared per square foot }\end{array}$ & 47.88026 & pascal-seconds squared \\
\hline standard free fall ( $g^{\prime} s$ ) & 9.80665 & metres per second squared \\
\hline
\end{tabular}




\section{Introduction}

1. Intake towers in the outlet works of many existing and planned Corps of Engineers projects are subjected to earthquake hazards ranging from minor to severe. The Corps has traditionally evaluated the seismic safety of these intake towers through a dated, gross approximation of earthquake loading known as the seismic coefficient method. The research discussed in this report was undertaken to develop practical procedures for analysis of intake tower seismic response which would be consistent with the current understanding of earthquake loading and structural response. However, the analytical procedures developed require that some undesirable approximations of seismic response be employed. These are recommended as topics for further study.

\section{$\underline{\text { Seismic Coefficient Method }}$}

2. The seismic coefficient method (Office, Chief of Engineers 1964) is a procedure used to calculate an approximate static representation of earthquake forces which can be applied to intake towers and other structures for use in structural analyses. The earthquake load is computed by multiplying a dimensionless seismic coefficient by the distributed weight of the intake tower. The magnitude of the seismic coefficient is determined by the seismic hazard associated with generalized geographic regions. Once the static representation of the earthquake forces has been calculated, it is applied to the intake tower, and the shears and moments are computed from equilibrium requirements.

3. A major deficiency of the seismic coefficient method is the inherent assumption of rigid body motion. Since an intake tower is not rigid, this procedure ignores the dependency of structure response on the natural frequencies of the tower and the frequency content of 
the earthquake ground motion. Another shortcoming is the lack of accuracy in the specification of the seismic coefficient. The same value is assigned to a large geographic region. Hence, it does not account for the seismic characteristics of particular locations. Therefore, considering these limitations, the seismic coefficient method of analysis cannot be expected to accurately predict the response of an intake tower subjected to an earthquake loading.

\section{Design Earthquake}

4. The first step in seismic design is choosing the level of the seismic load effect any structure might experience during its life. That this effect cannot be adequately represented by a common static load for all structures can be shown by examining the single-degreeof-freedom (SDOF) idealization of a structure in Figure 1. If

$$
\begin{aligned}
\mathrm{m}= & \text { mass of the structure } \\
\mathrm{c}= & \text { damping constant of the structure } \\
\mathrm{k}= & \text { stiffness of the structure } \\
\mathrm{u}(\mathrm{t})= & \text { displacement of the structure relative to the } \\
& \text { ground } \\
\dot{\mathrm{u}}(\mathrm{t})= & \text { velocity of the structure relative to the ground } \\
\ddot{\mathrm{u}}(\mathrm{t})= & \text { acceleration of the structure relative to the } \\
& \text { ground } \\
\ddot{\mathrm{u}}_{\mathrm{g}}(\mathrm{t})= & \text { ground acceleration }
\end{aligned}
$$

the equation of motion of this structure is

$$
m \ddot{u}+c \dot{u}+k u=-m \ddot{u}_{g}(t)
$$

Therefore, the internal seismic force felt by the structure

$$
k u=-m\left[\ddot{u}_{g}(t)+\ddot{u}(t)\right]-c \dot{u}(t)
$$

is a time-dependent function of its stiffness, damping, and inertial properties as well as of the earthquake ground motion. 
Figure 1. Single-degree-of-freedom idealization of a structure

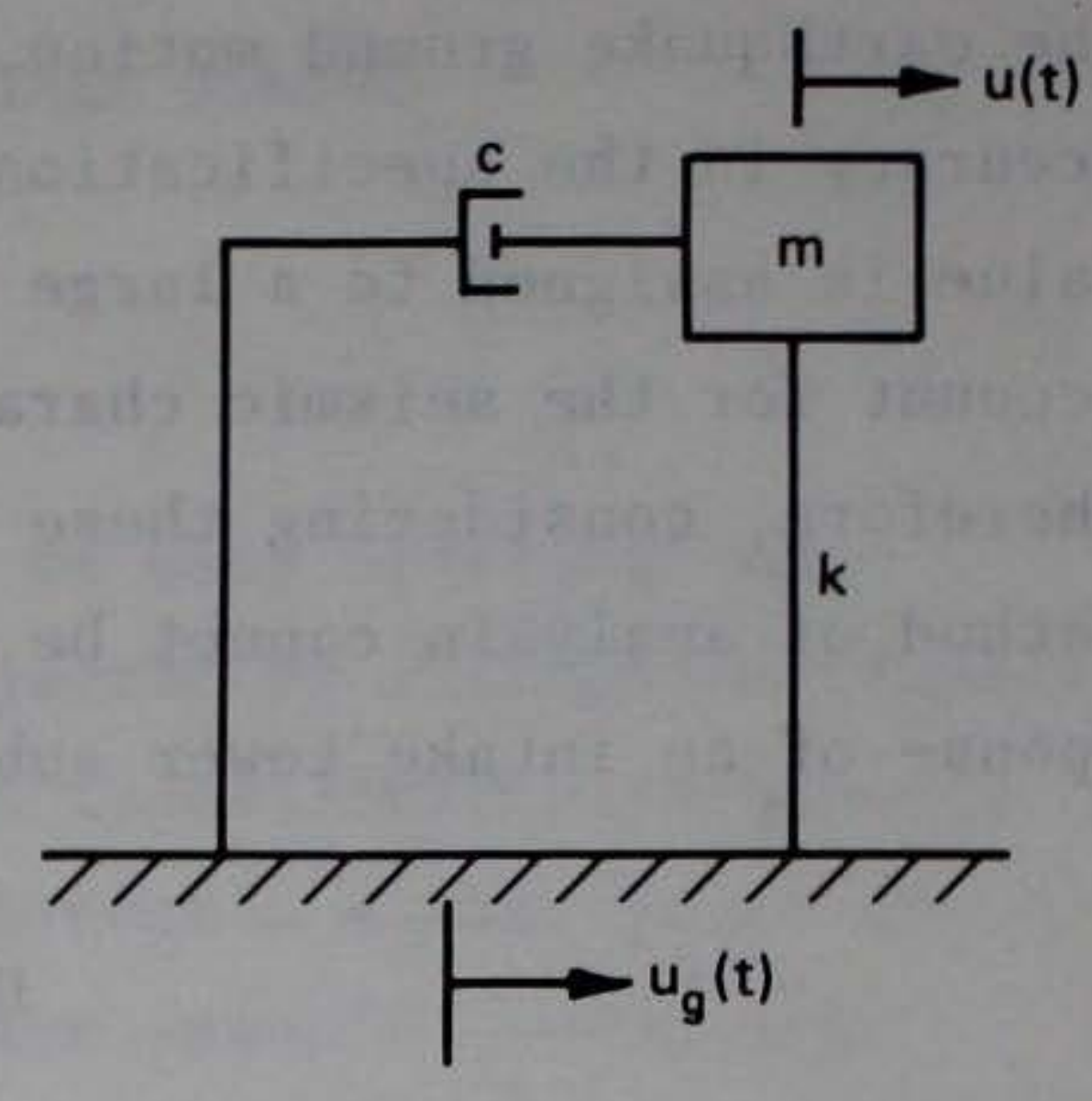

5. However, Equation 1 does suggest that one method of representing the seismic force is through the specification of time histories of ground acceleration $\ddot{u}_{g}(t)$. The time histories may be taken from actual earthquakes, such as shown in Figure 2, or may be randomly generated by computer algorithms. This representation of the earthquake loading is usually necessary for structures characterized by a nonlinear response.

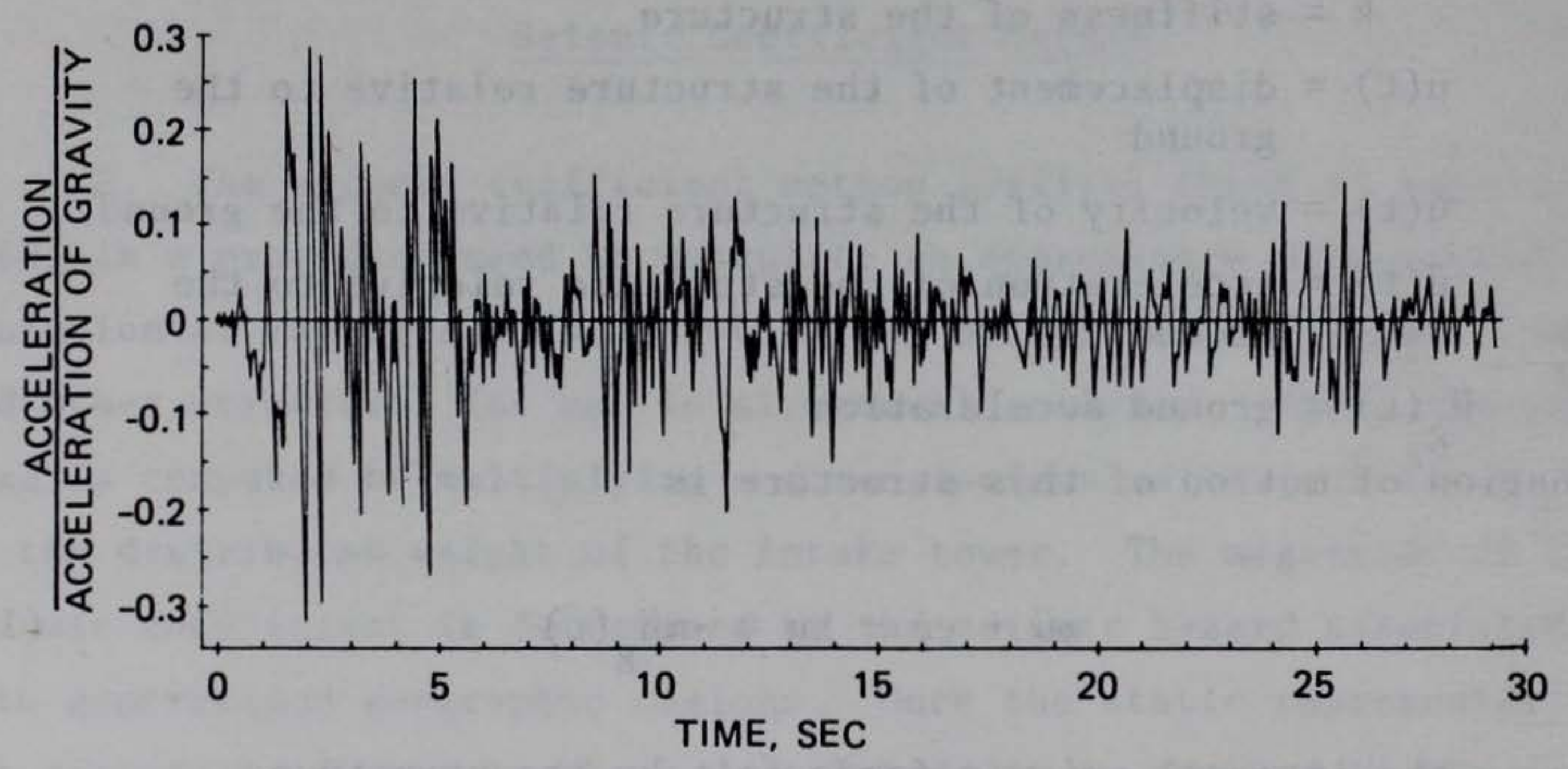

Figure 2. Accelerogram from the E1 Centro earthquake, 18 May 1940 (NS component)

6. The response spectrum is another way of specifying the seismic load effect. A response spectrum is a graphical representation of the maximum response of all linear SDOF systems for a specific ground motion at a particular level of damping (Clough and Penzien 1975). 
For each time history, there is a unique response spectrum as shown in Figure 3. A response spectrum for use in design is sometimes obtained by smoothing the spectra of several actual time histories.

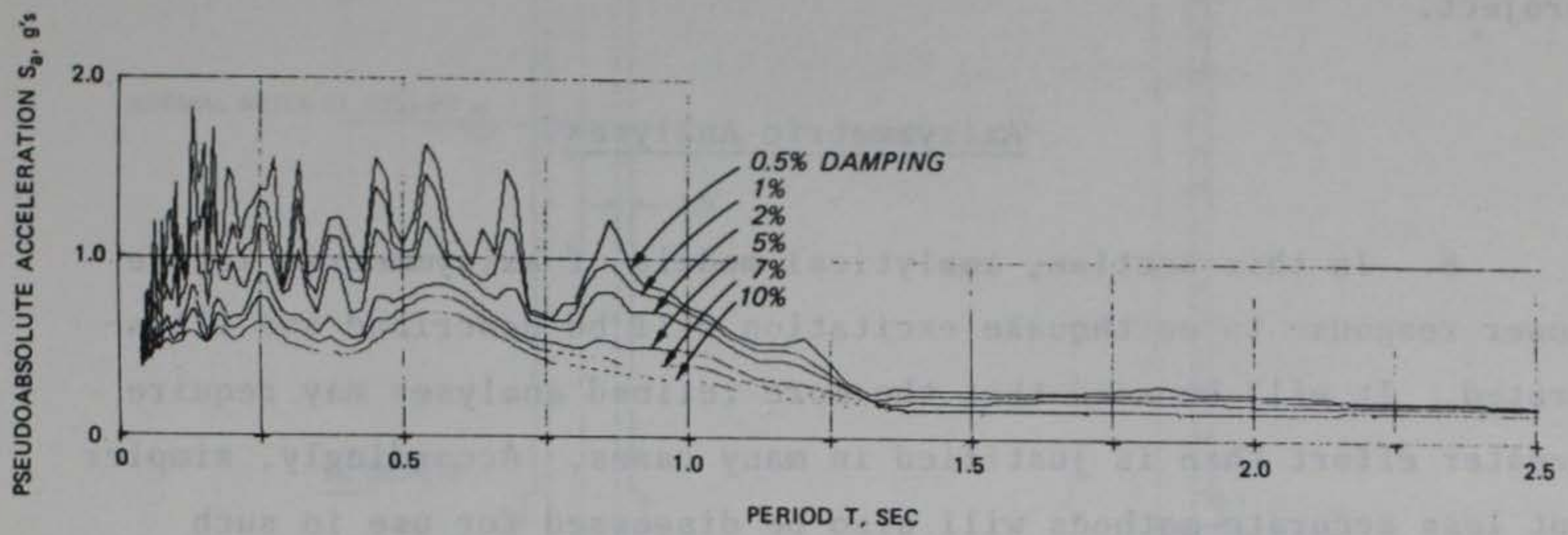

Figure 3. Response spectra for the El Centro earthquake, 18 May 1940 (NS component)

7. There are a number of accepted methods at present for determining design earthquakes for different location (Hays 1980; Krinitzsky*). These methods consider the following factors in prescribing an ensemble of time histories and/or the response spectrum appropriate for a particular site:

a. Geologic, geophysical, and seismological data about the site.

b. Presence or absence of recognizable active faults.

c. Estimated upper bound magnitudes for earthquakes that might be produced by these faults.

d. Peak motions associated with these events.

e. Selection of a proper attenuation of these motions from source to site.

f. Effects of site characteristics on these motions.

g. Likelihood of exceeding various ground motions using probabilistic procedures.

While a structural engineer is primarily interested in the prescribed design earthquake, he should appreciate the professional judgments

* E. L. Krinitzsky, "Essentials for Specifying Earthquake Motions in Engineering Design," U. S. Army Engineer Waterways Experiment Station, Vicksburg, Miss., 1981. 
involved in the procedure that led to this prescription. Such an appreciation will permit him to appropriately tailor the conservatism of his structural analysis to assure the public a safe and economical project.

\section{$\underline{\text { Axisymmetric Analyses }}$}

8. In this section, analytical models of axisymmetric intake tower response to earthquake excitation will be described and illustrated. It will be seen that the more refined analyses may require greater effort than is justified in many cases. Accordingly, simpler but less accurate methods will also be discussed for use in such situations.

Analysis with program EATSW

9. The most sophisticated model presently available considers an axisymmetric elastic tower surrounded by an infinitely extending reservoir and standing on a rigid foundation (Liaw and Chopra 1975). A special-purpose finite element computer code (EATSW) employing substructuring and fast Fourier transform techniques has been developed to implement this analytical model (Liaw and Chopra 1973). EATSW numerically evaluates the response of this analytical model to the horizontal component of an earthquake ground motion using either explicit mathematical solutions if the structure-water interface is cylindrical or a finite element system if the interface geometry is more complex. This code is capable of including any number of modes of vibration desired by the user. EATSW outputs the complete time history of the displacements and stresses throughout the structure. Figures 4-13 show two different intake towers, two different seismic motions, and the responses of these towers to these motions as calculated in Liaw and Chopra (1973). In the EATSW analyses, only three modes of vibration of the San Bernardino Tower and four modes of vibration of the Briones Tower were found to be adequate. For subsequent comparison with simpler analyses, the stress output from EATSW was converted to shears and moments using the relationships 


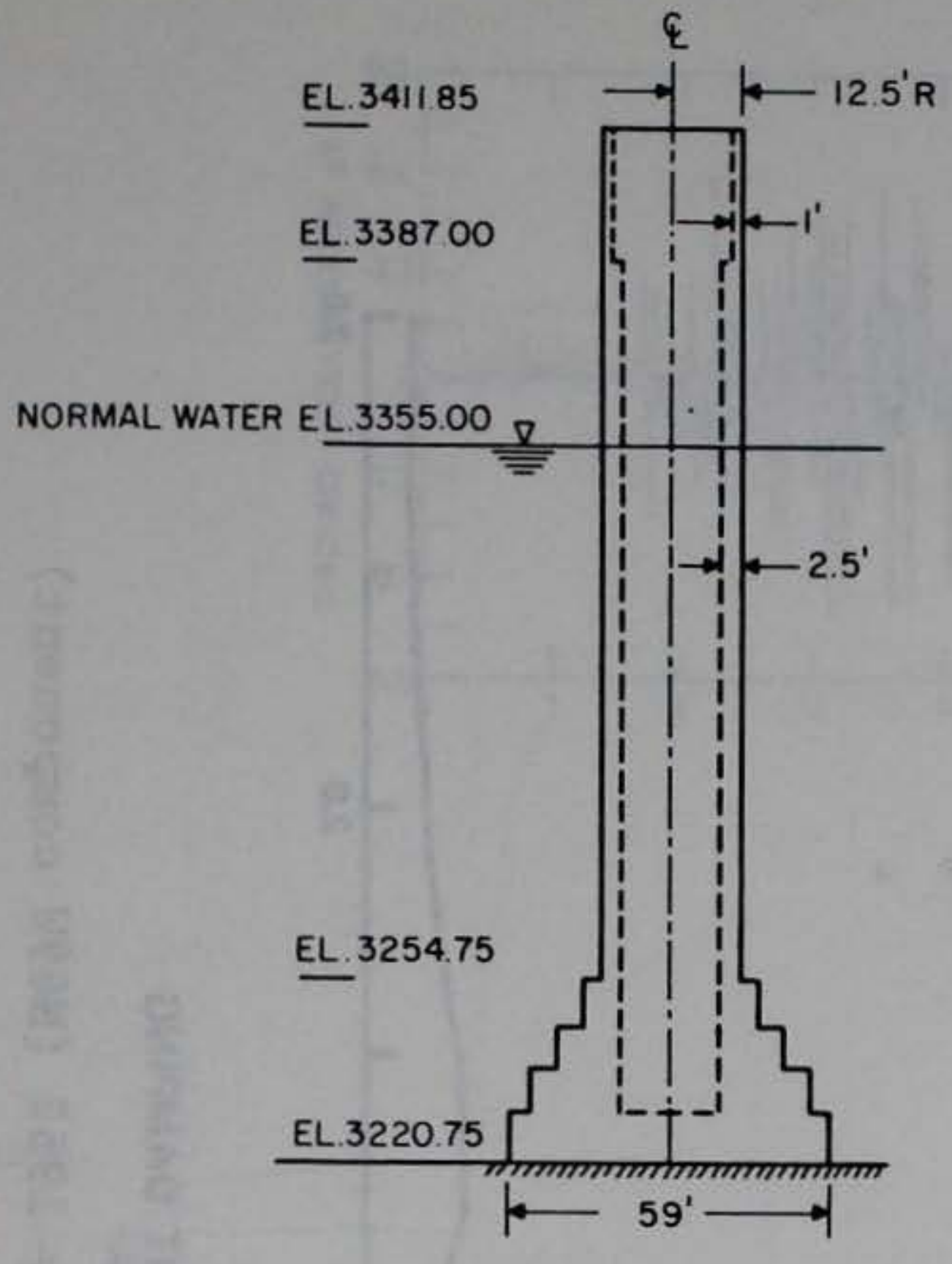

a. SAN BERNARDINO TOWER

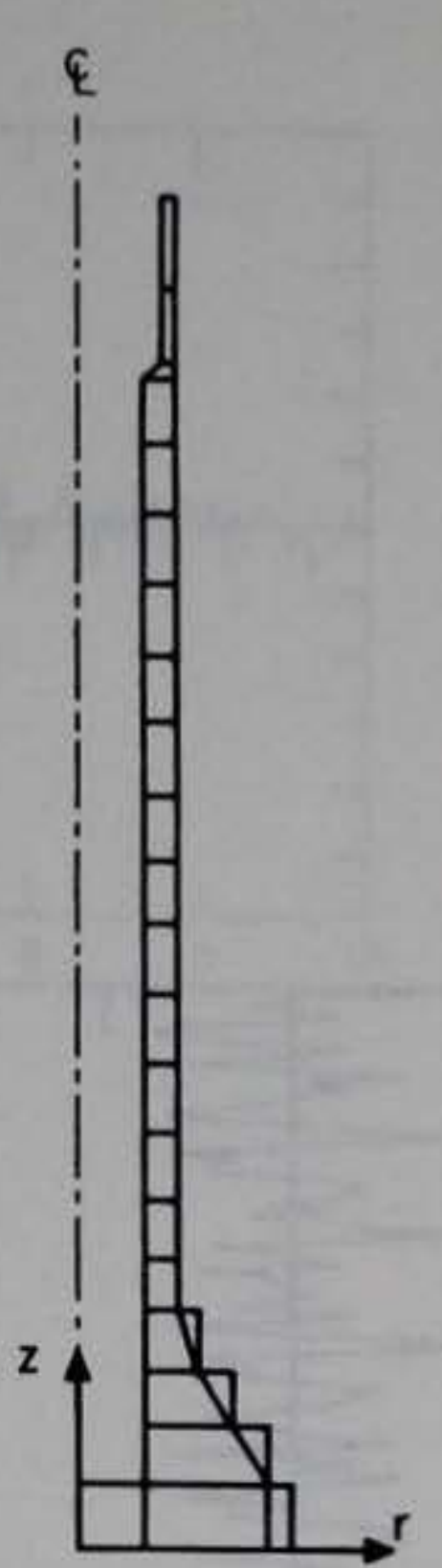

b. FINITE ELEMENT IDEALIZATION

Figure 4. San Bernardino tower and its finite element idealization (elevations (EL) are in feet referred to mean sea level)

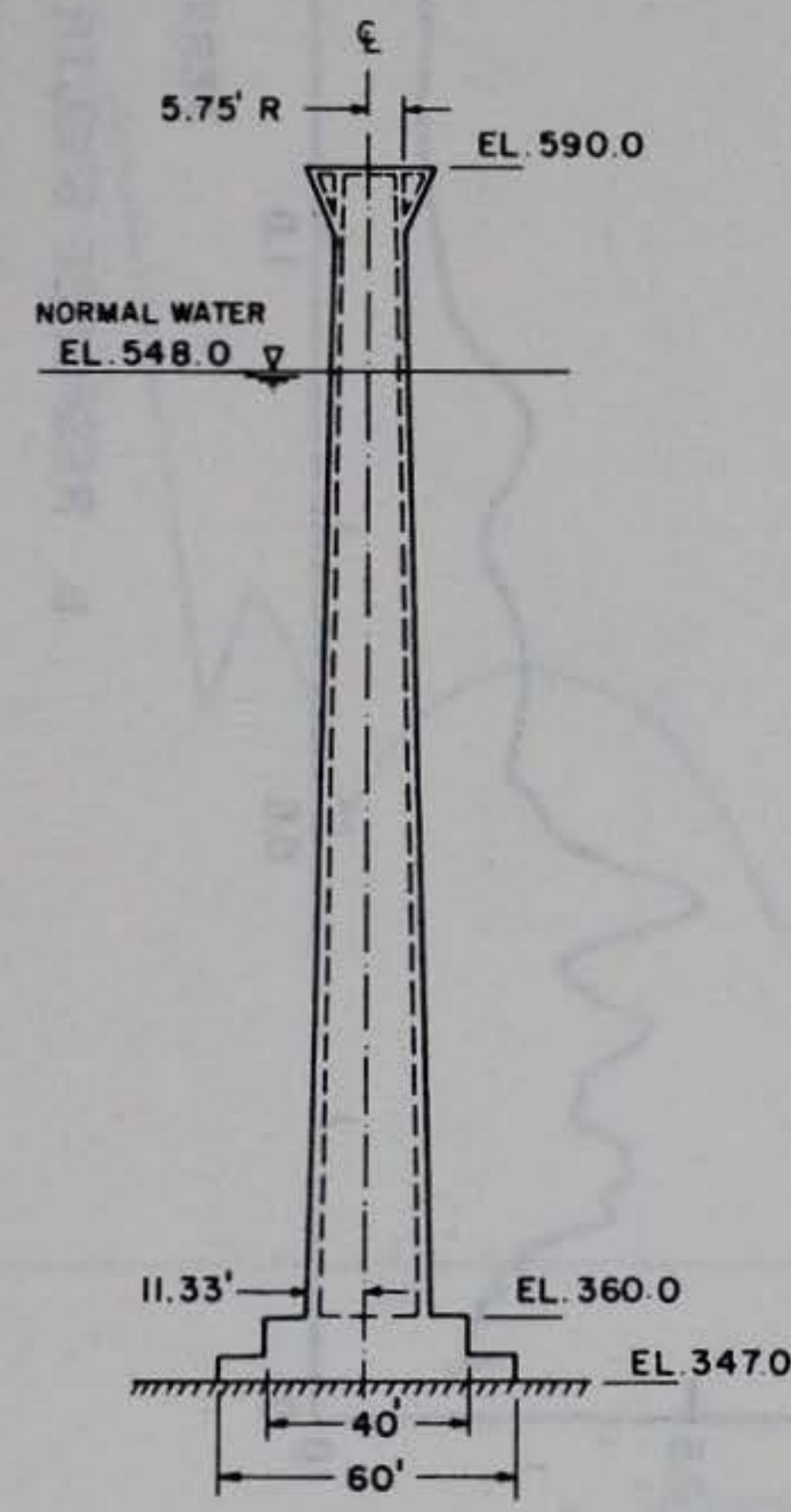

a. BRIONES TOWER

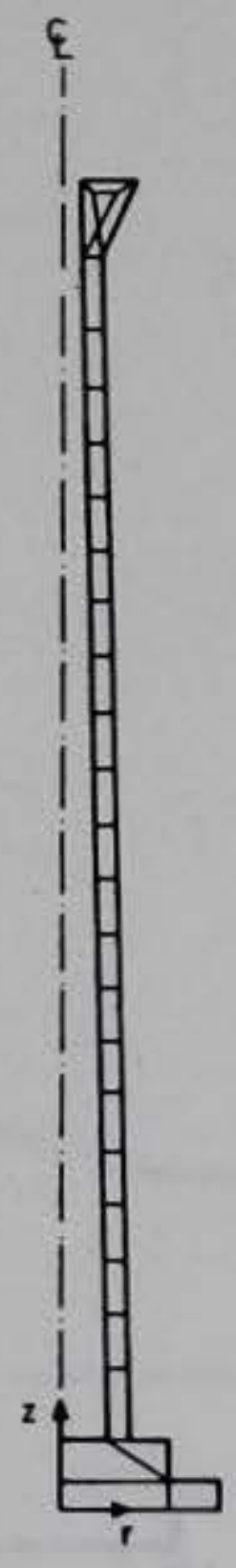

b. FINITE ELEMENT IDEALIZATION IDEALIZATION

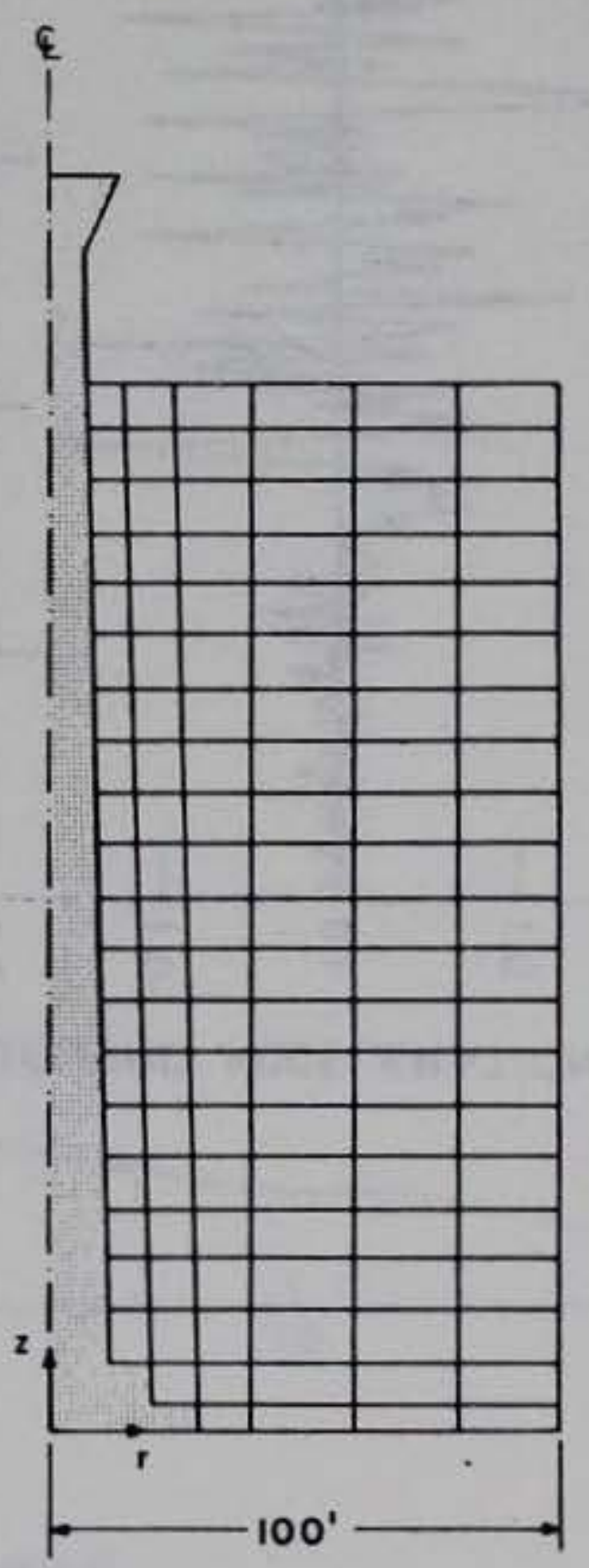

c. FINITE ELEMENTI IDEALZZATION:OF THE SURROUNDING WATER

Figure 5. Briones tower and finite element idealizations for the tower and surrounding water 


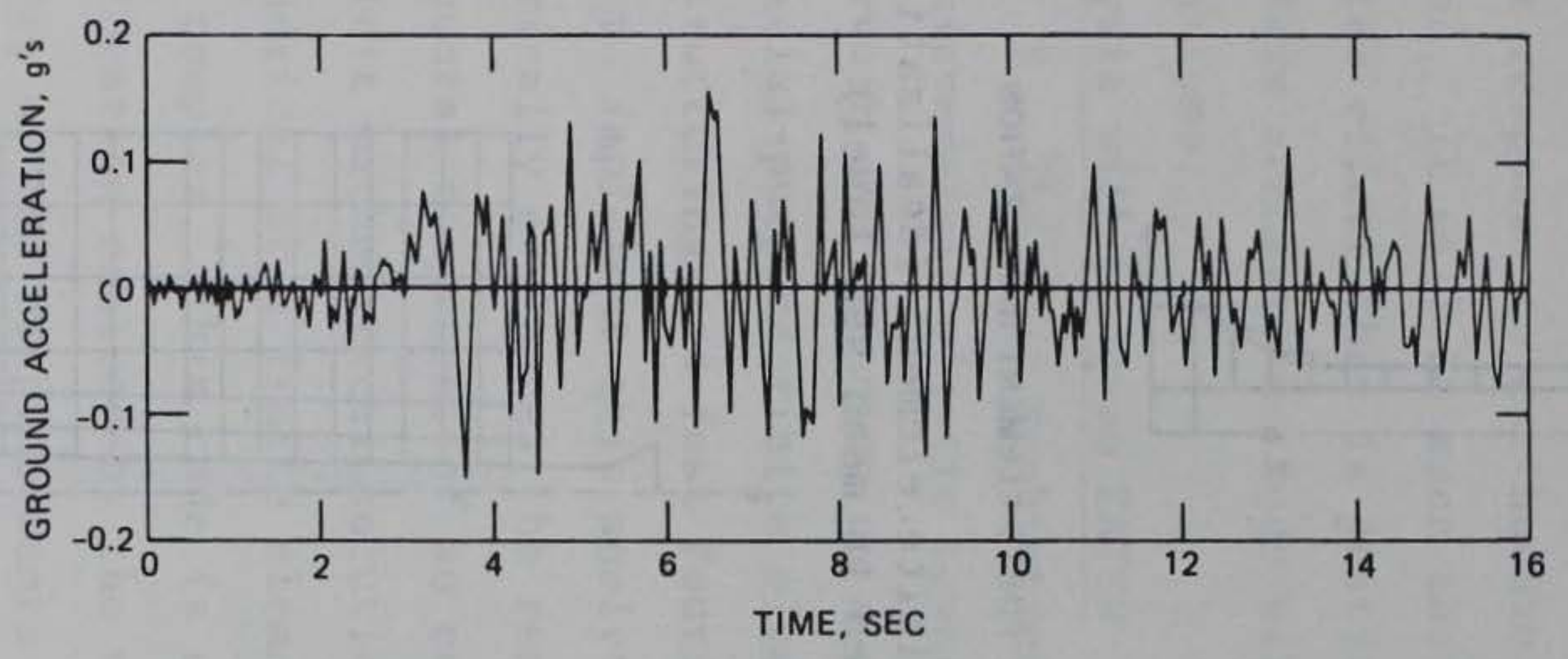

a. ACCELEROGRAM

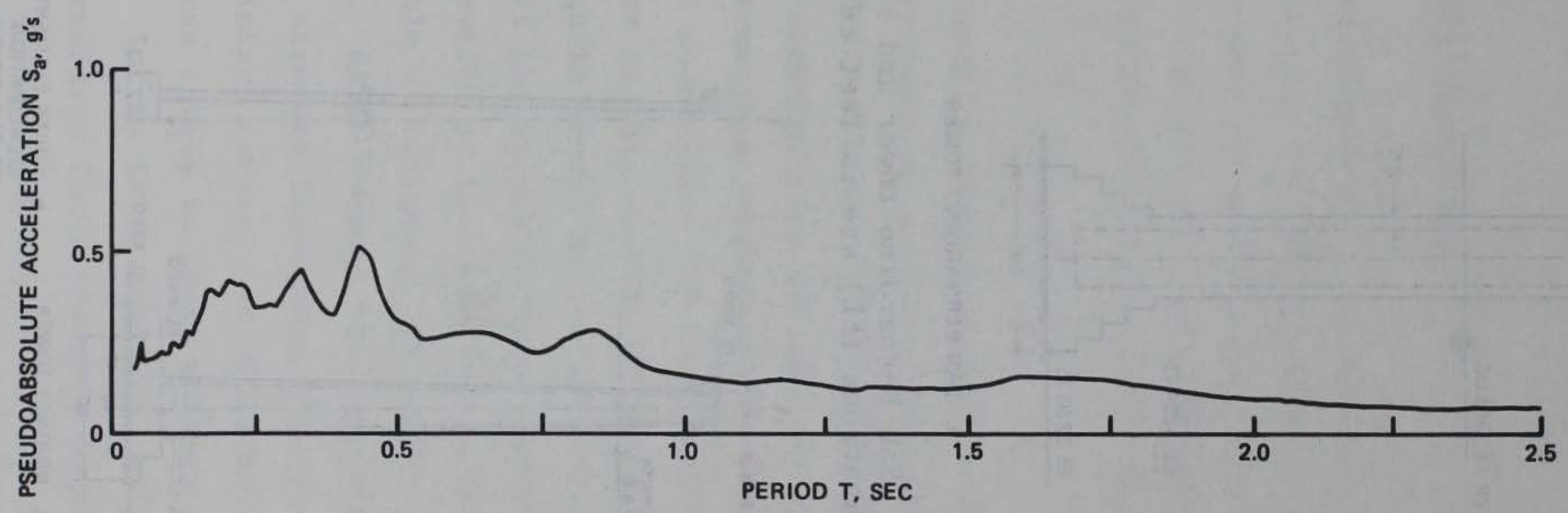

b. RESPONSE SPECTRUM, 5 PERCENT DAMPING

Figure 6. Taft, Calif., earthquake, 21 July 1952 (N69W component) 


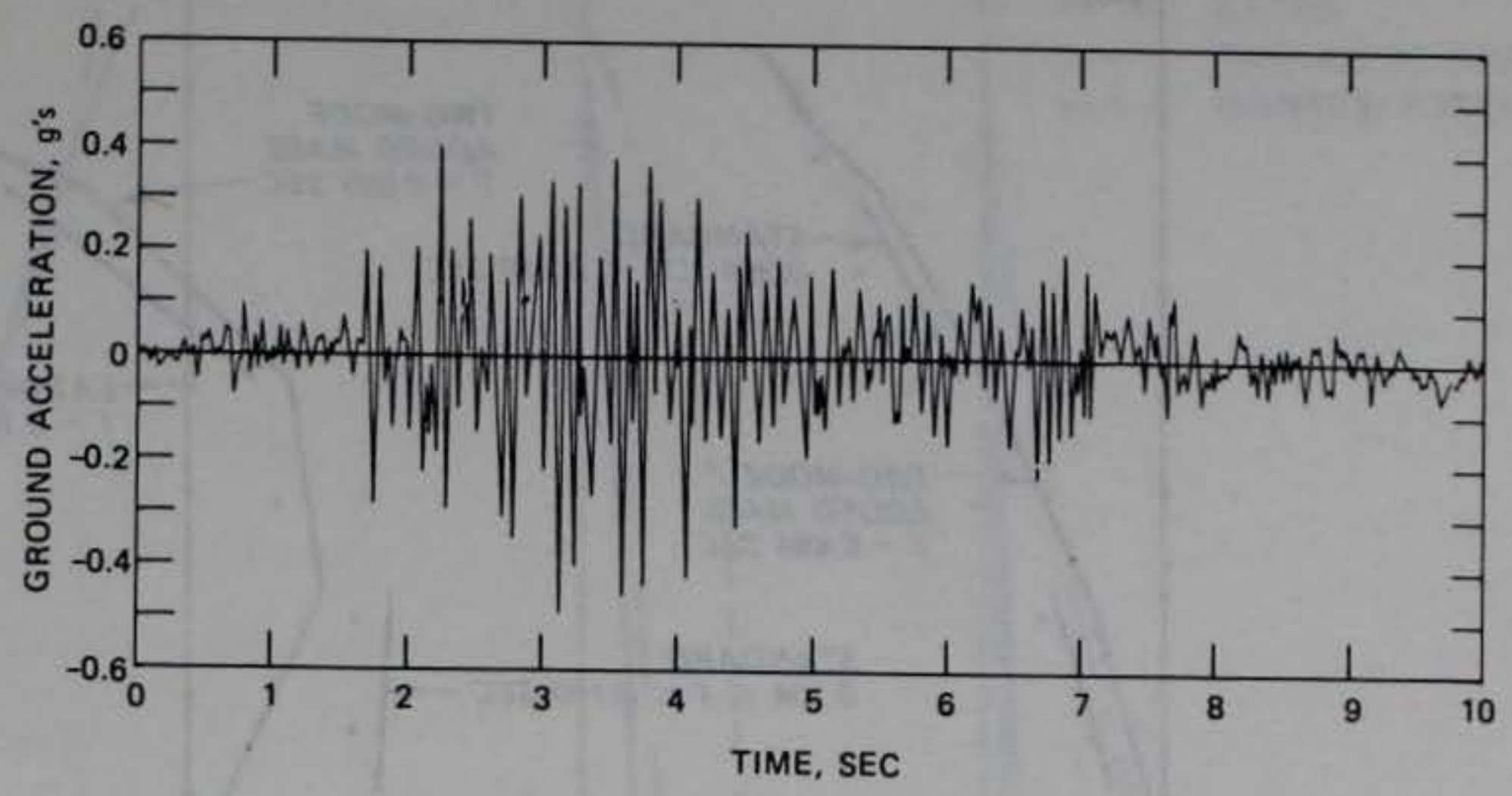

a. ACCELEROGRAM

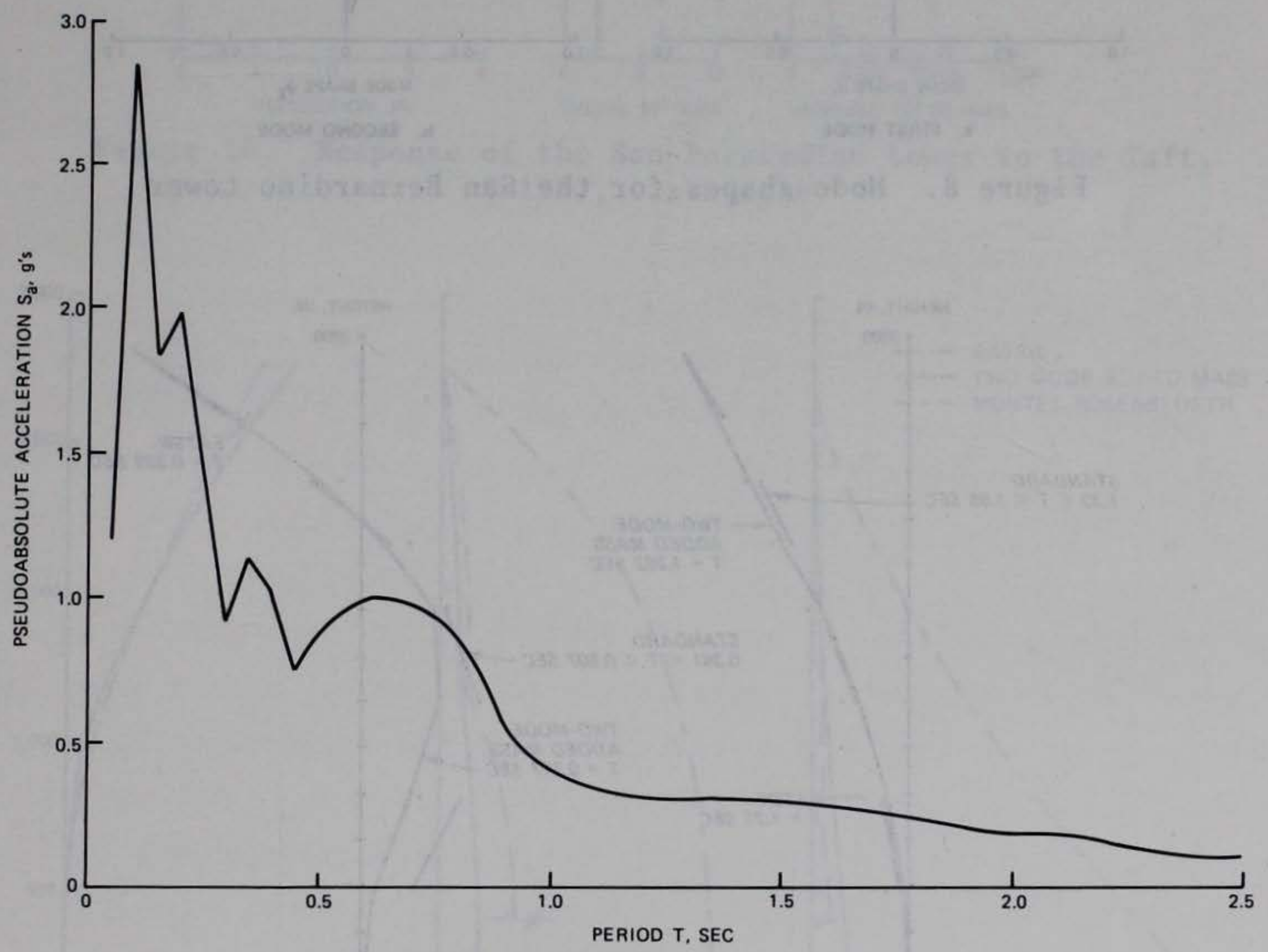

b. RESPONSE SPECTRUM, 5 PERCENT DAMPING

Figure 7. Koyna, India, earthquake, 11 December 1967 (transverse component) 


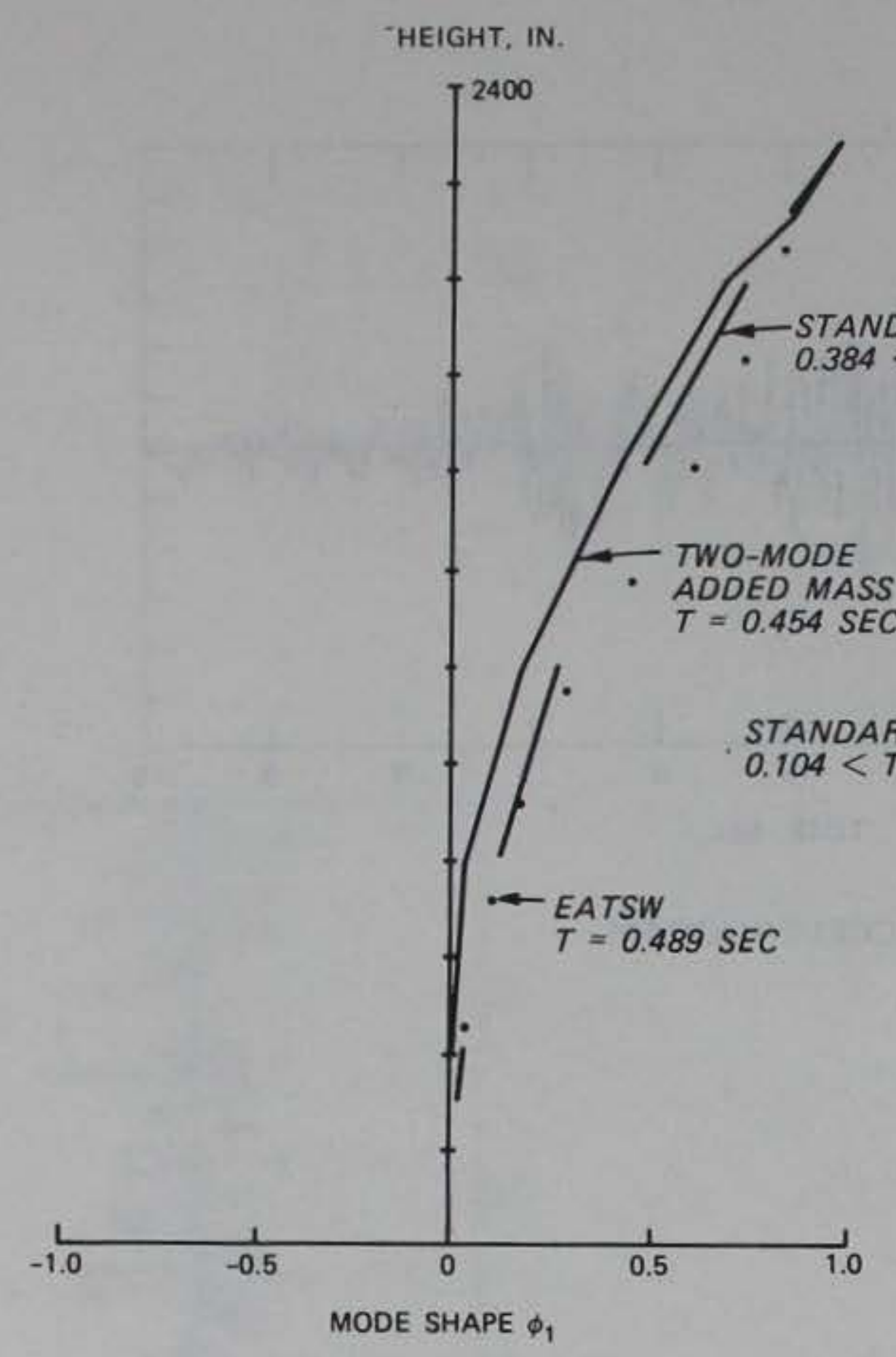

a. FIRST MODE

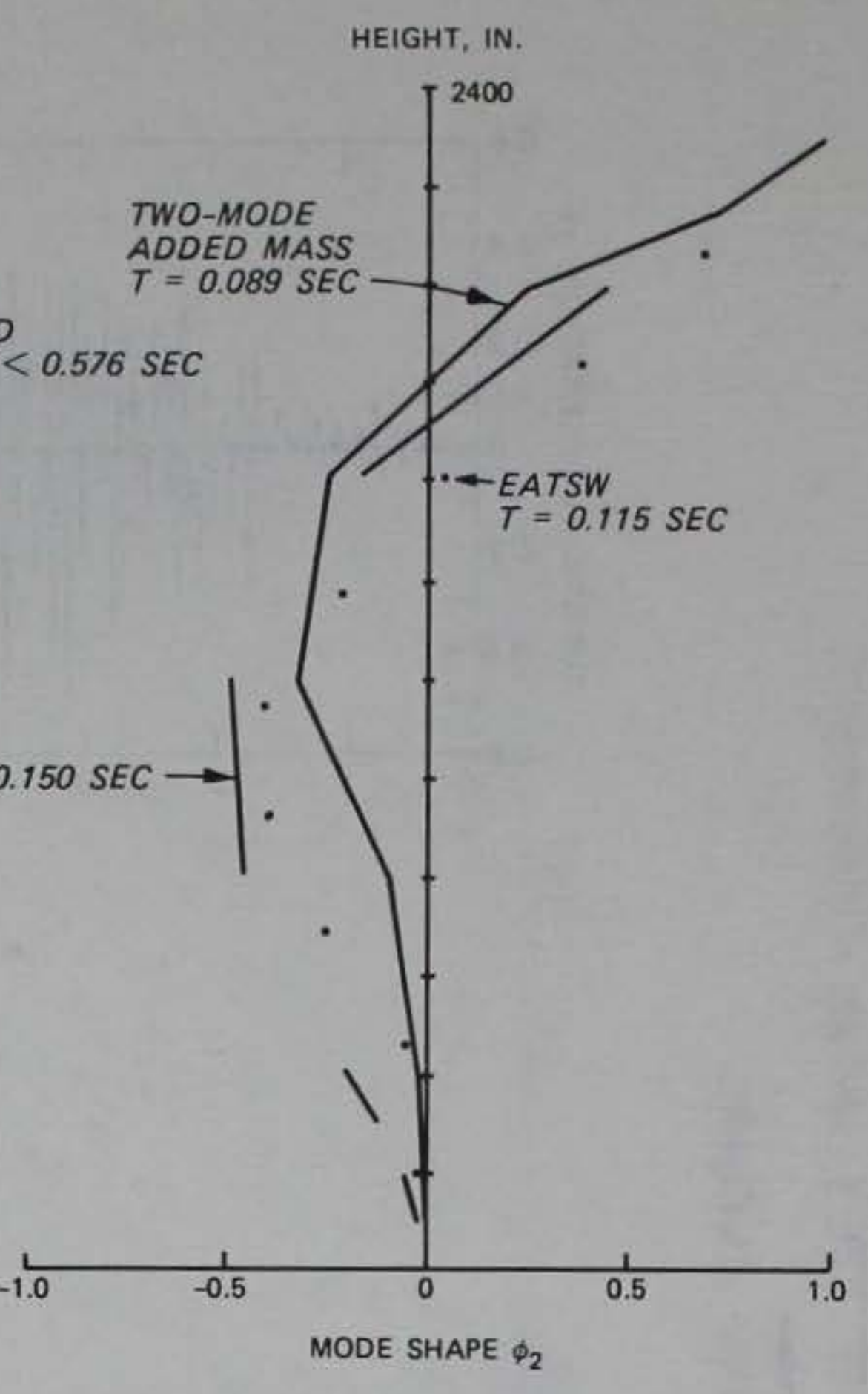

b. SECOND MODE

Figure 8. Mode shapes for the San Bernardino tower

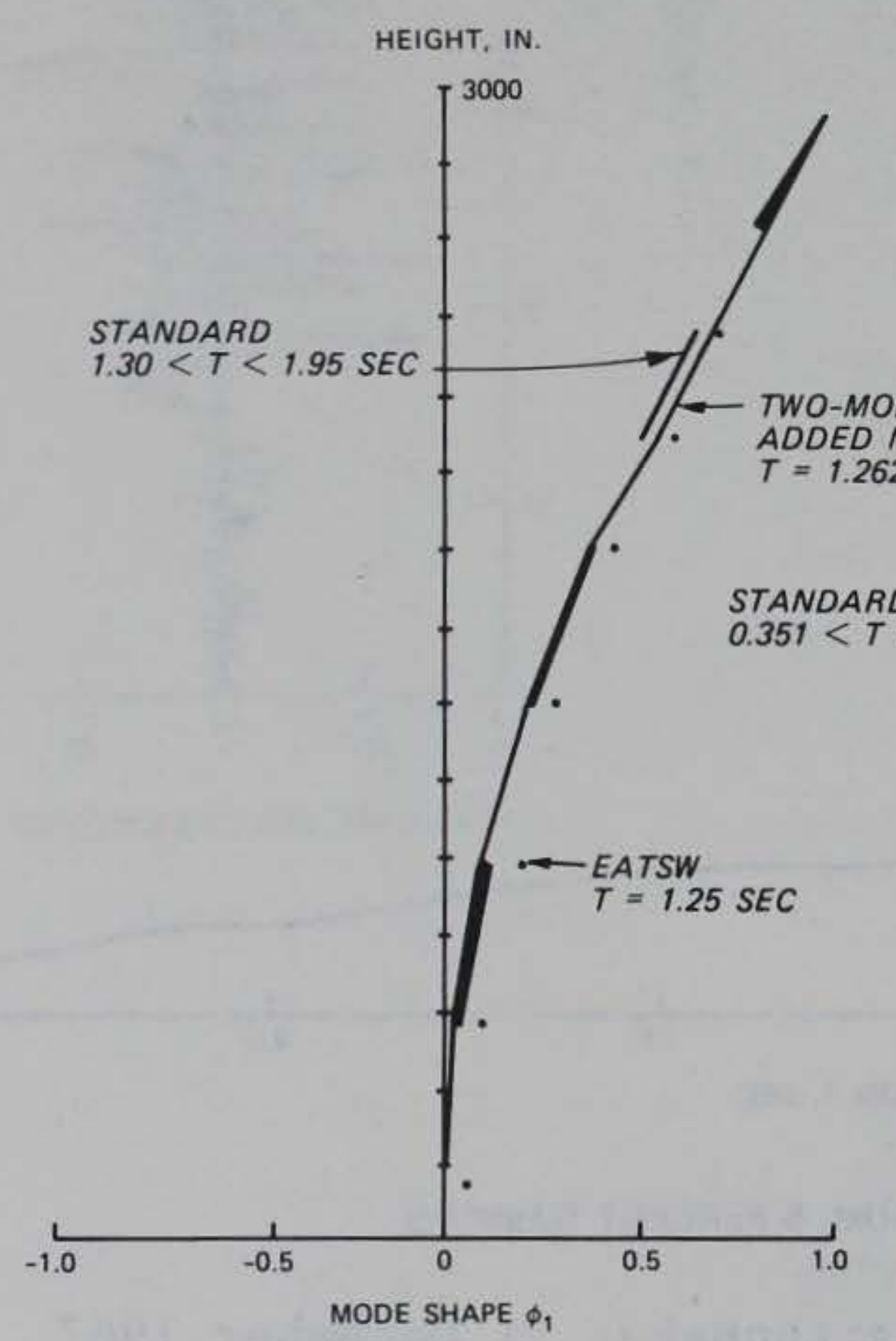

a. FIRST MODE

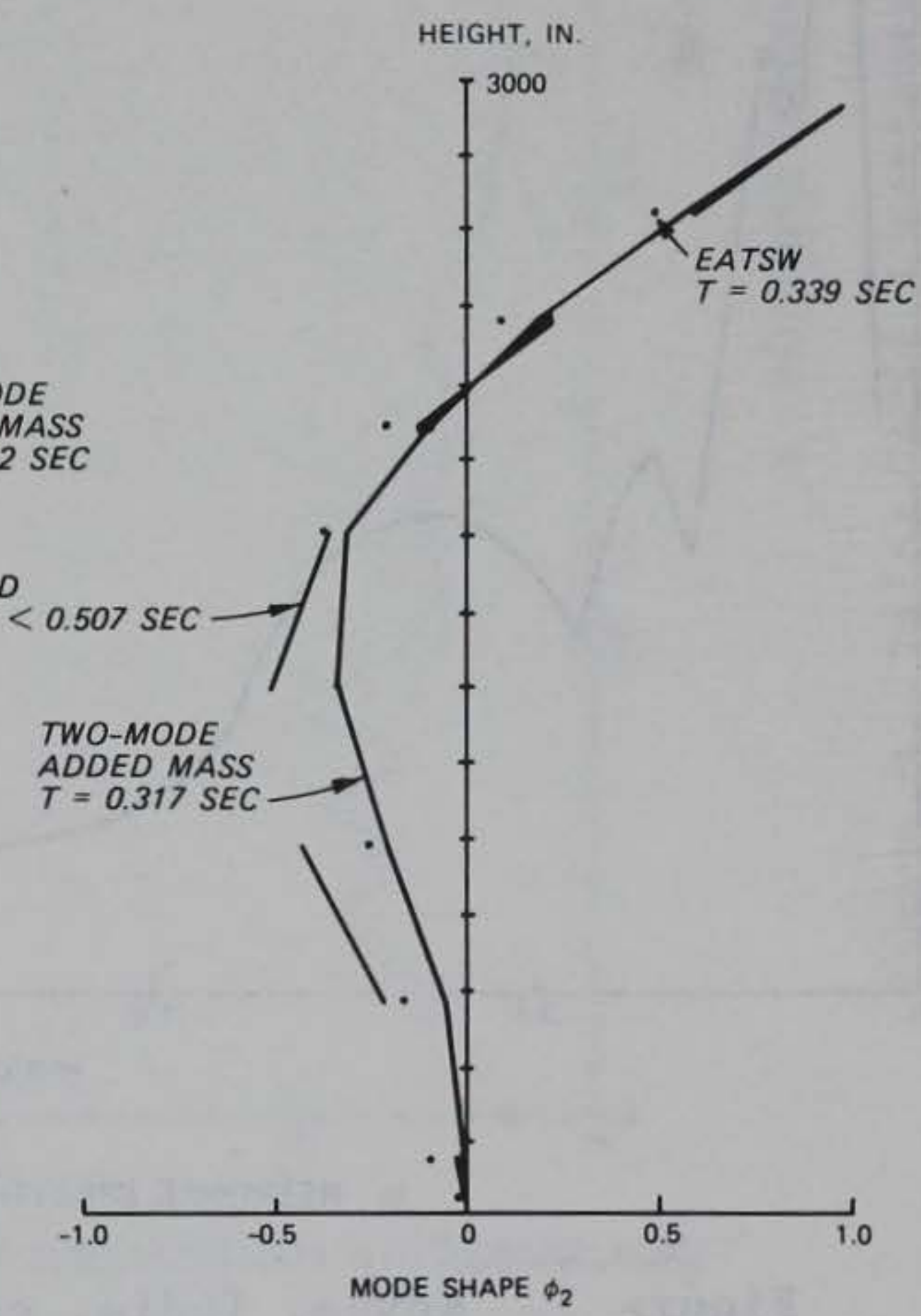

b. SECOND MODE

Figure 9. Mode shapes for the Briones tower 

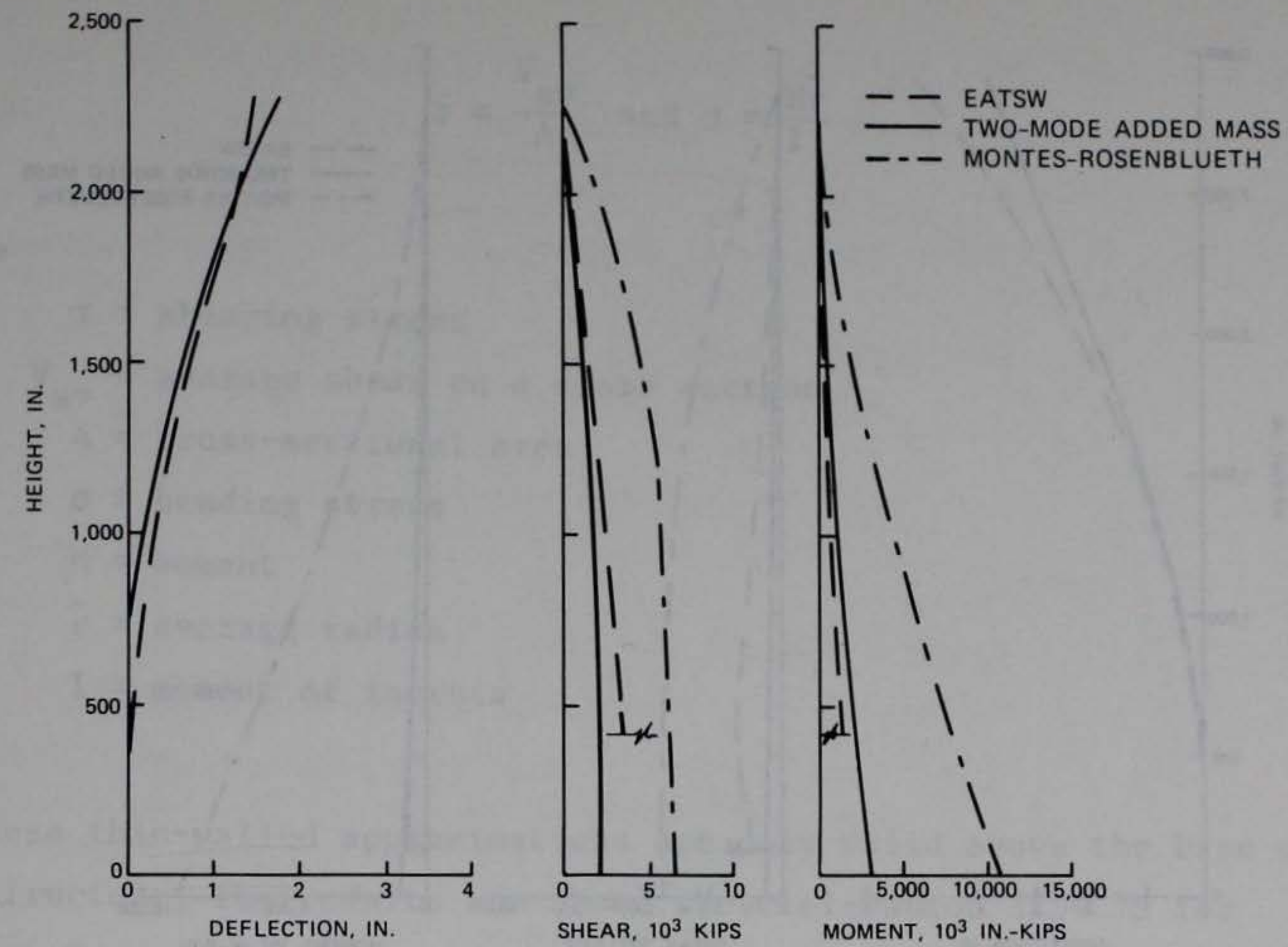

Figure 10. Response of the San Bernardino tower to the Taft, Calif., earthquake
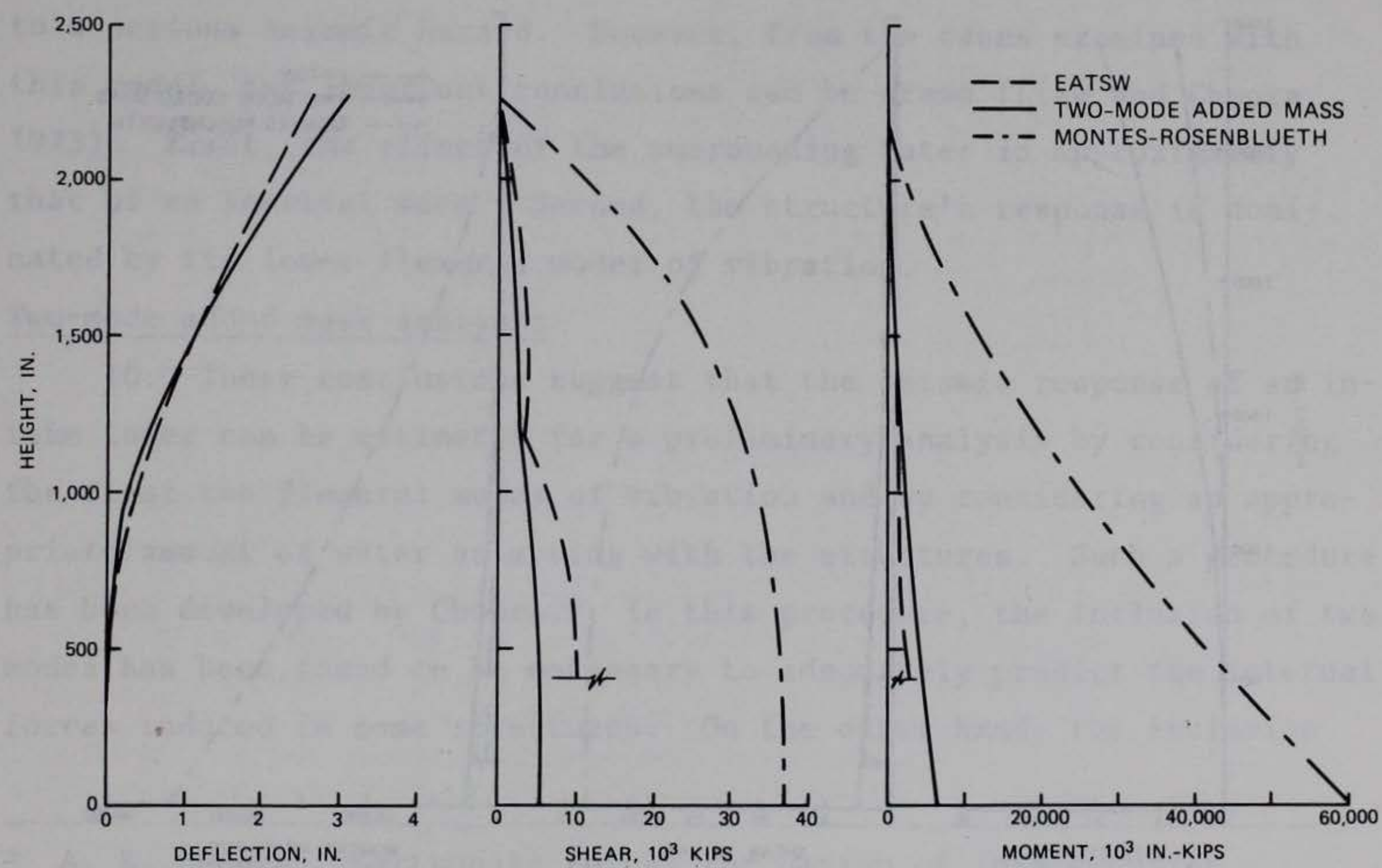

Figure 11. Response of the San Bernardino tower to the Koyna, India, earthquake 

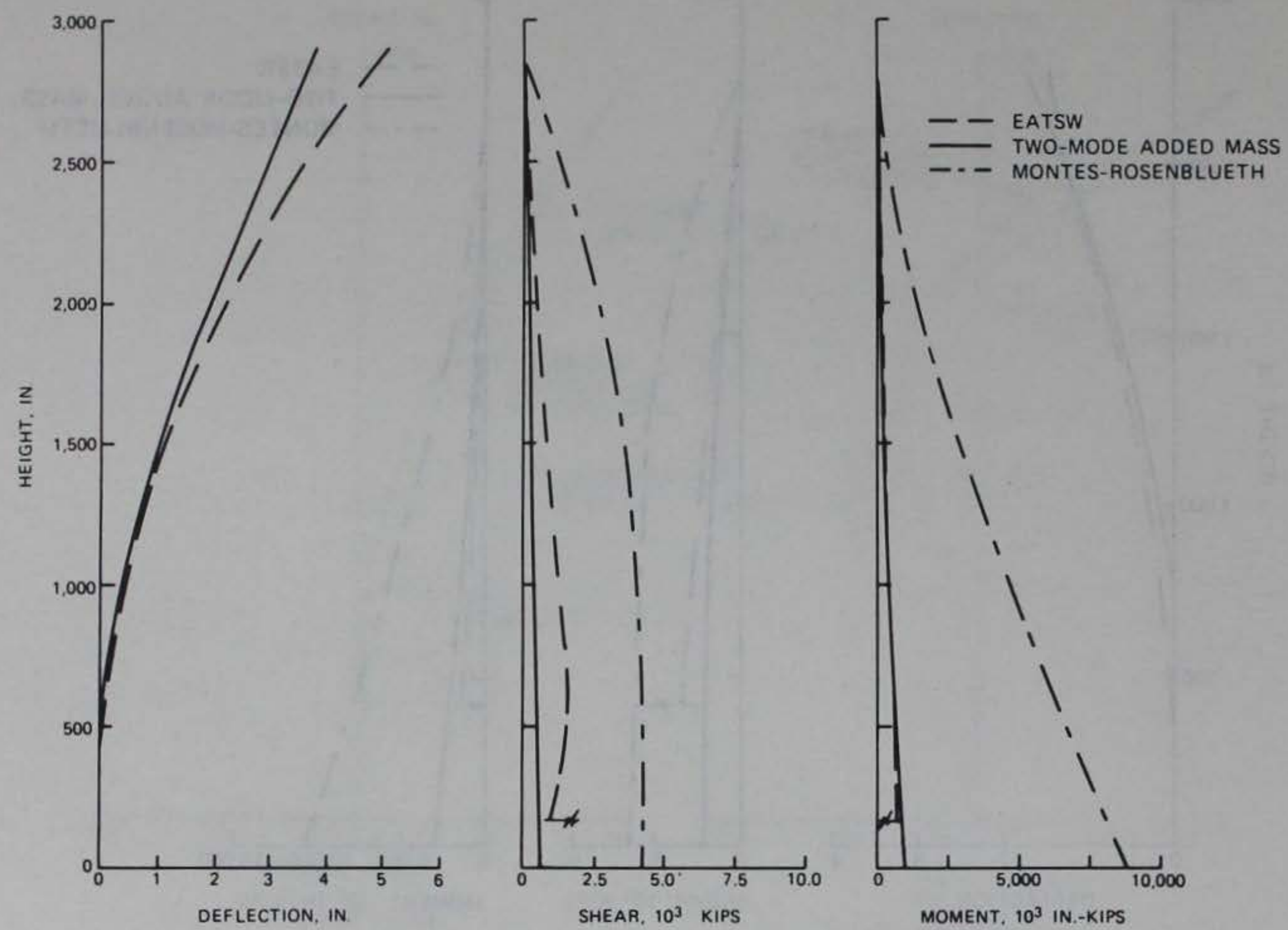

Figure 12. Response of the Briones tower to the Taft, Calif., earthquake
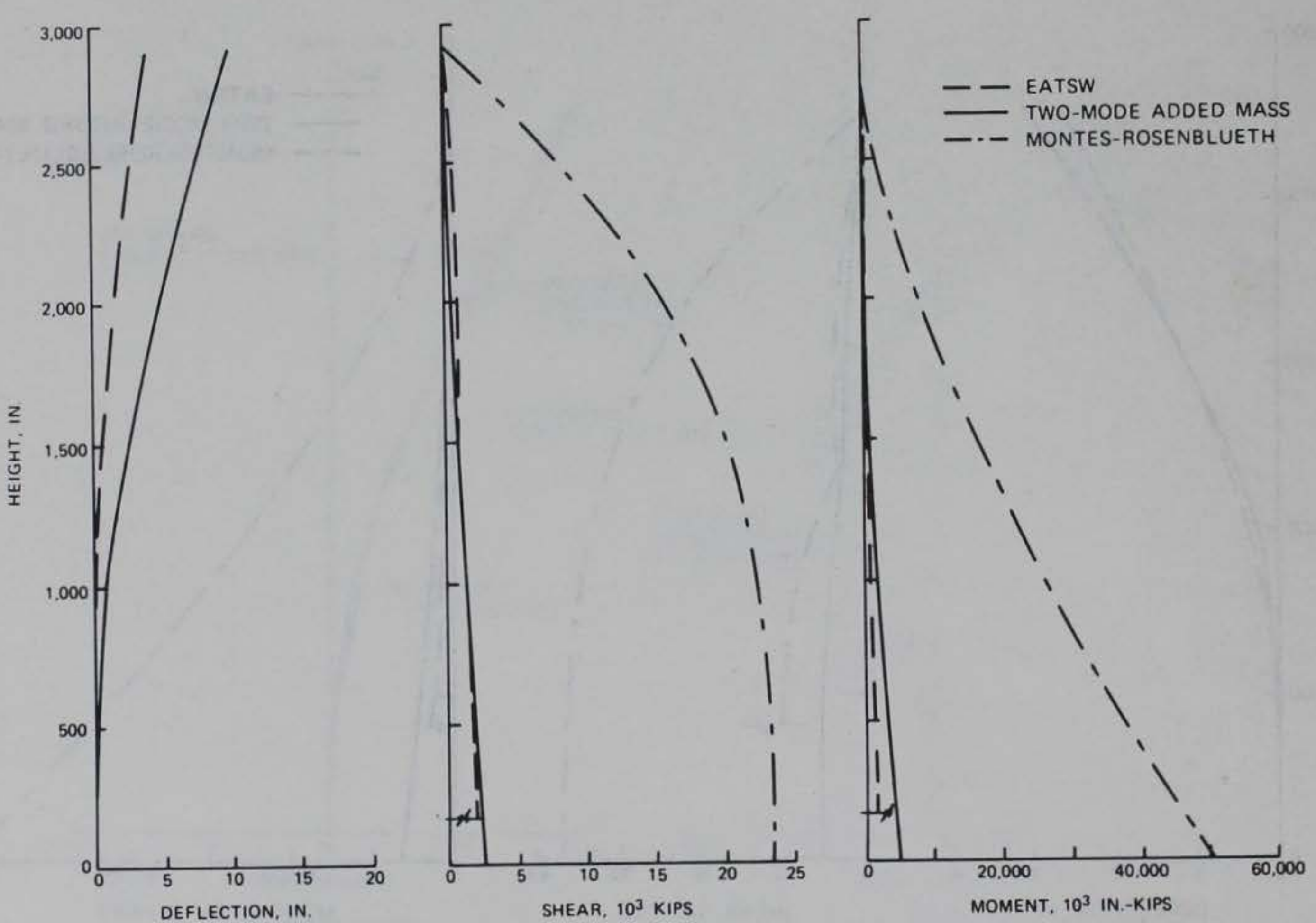

Figure 13. Response of the Briones tower to the Koyna, India, earthquake 


$$
\tau=\frac{V_{\text {av }}}{A} \text { and } \sigma=\frac{M \bar{r}}{I}
$$

where

$$
\begin{aligned}
\tau & =\text { shearing stress } \\
V_{\text {av }} & =\text { average shear on a cross section } \\
\mathrm{A} & =\text { cross-sectional area } \\
\sigma & =\text { bending stress } \\
M & =\text { moment } \\
\bar{r} & =\text { average radius } \\
I & =\text { moment of inertia }
\end{aligned}
$$

As these thin-walled approximations are only valid above the base of the structure, the results are shown above elevation 3254.75 for the San Bernardino Tower and above elevation 360.0 for the Briones Tower. Such sophisticated models may be required for the final safety evaluation of an exceptionally important structure subjected to a serious seismic hazard. However, from the cases examined with this model, two important conclusions can be drawn (Liaw and Chopra 1973). First, the effect of the surrounding water is approximately that of an inertial mass. Second, the structure's response is dominated by its lower flexural modes of vibration.

Two-mode added mass analysis

10. These conclusions suggest that the seismic response of an intake tower can be estimated for a preliminary analysis by considering the first two flexural modes of vibration and by considering an appropriate amount of water as moving with the structures. Such a procedure has been developed by Chopra.* In this procedure, the inclusion of two modes has been found to be necessary to adequately predict the internal forces induced in some structures. On the other hand, the inclusion

* A. K. Chopra, "Earthquake Forces for Design of Intake-Outlet Towers," manuscript submitted to the U. S. Army Engineer Waterways Experiment Station, Vicksburg, Miss., 1981. 
of more than two modes has been judged to be inappropriate in light of the approximation of hydrodynamic interaction. The steps in the procedure are as follows:

a. Define the structural properties of the tower-reservoir system:

(1) The virtual mass per unit length is:

$$
m(z)=m_{0}(z)+m_{i}(z)+m_{a}(z)
$$

where

$$
\begin{aligned}
\mathrm{m}_{0}(z)= & \text { mass of the tower by itself } \\
\mathrm{m}_{i}(z)= & \text { mass of the water inside the tower } \\
\mathrm{m}_{\mathrm{a}}(\mathrm{z})= & \text { added mass to represent hydrodynamic effects } \\
& \text { of the surrounding water. This mass can be } \\
& \text { estimated with the aid of Figure } 14 \text { which } \\
& \text { represents the effects for the first mode } \\
& \text { of a uniform tower }
\end{aligned}
$$

(2) The flexural stiffness per unit length is EI(z).

(3) Damping ratios from an experimental study indicate that 5 percent may be a reasonable value for this parameter (Rea, Liaw, and Chopra 1975).

b. Compute the periods, $\mathrm{T}_{1}$ and $\mathrm{T}_{2}$, and mode shapes, $\phi_{1}(\mathrm{z})$ and $\phi_{2}(z)$, of the first two natural modes of vibration. Rayleigh's method (Biggs 1964) is particularly suited for this computation. Alternately, these dynamic characteristics can be estimated more quickly but with less accuracy from Figures 15 and 16 in which

$$
\bar{m}=\frac{\int_{0}^{H} m(z) d z}{H}
$$

is the average virtual mass per unit length. These design aids were constructed based on properties of nonuniform cantilever beams and those of several actual towers. The accuracy of these aids and of Rayleigh's method for the San Bernardino and Briones towers can be seen in Figures 8 and 9, respectively.

c. Compute the maximum response in the first and second modes of vibration: 


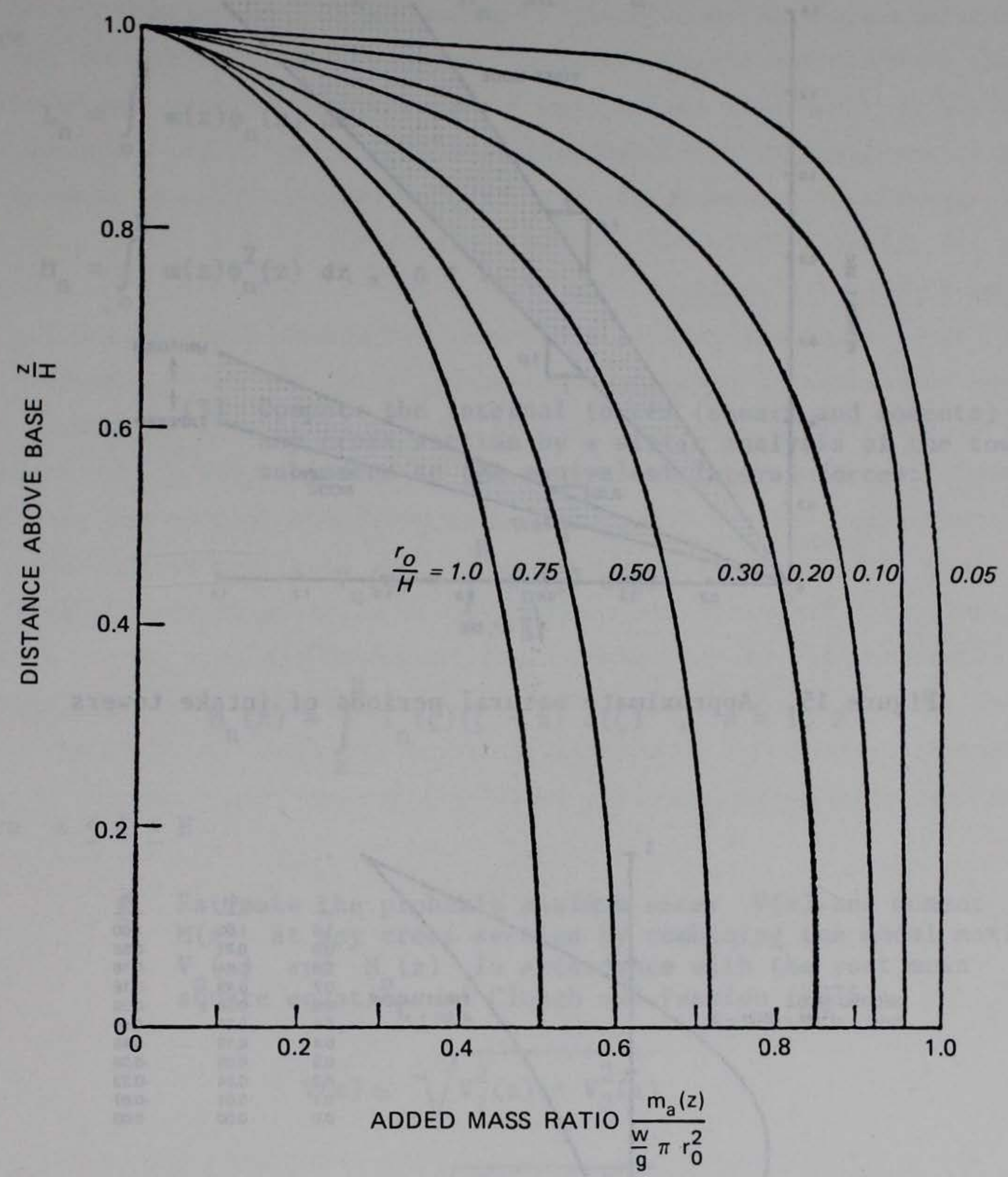

Figure 14. Added mass representing hydrodynamic effects of surrounding water

(1) For the period $T_{n}$ and damping ratio $\xi_{n}$, read the pseudoabsolute acceleration $S$ from the appropriate design response spectrum as discussed in paragraph 6 .

(2) Compute the equivalent lateral forces from 


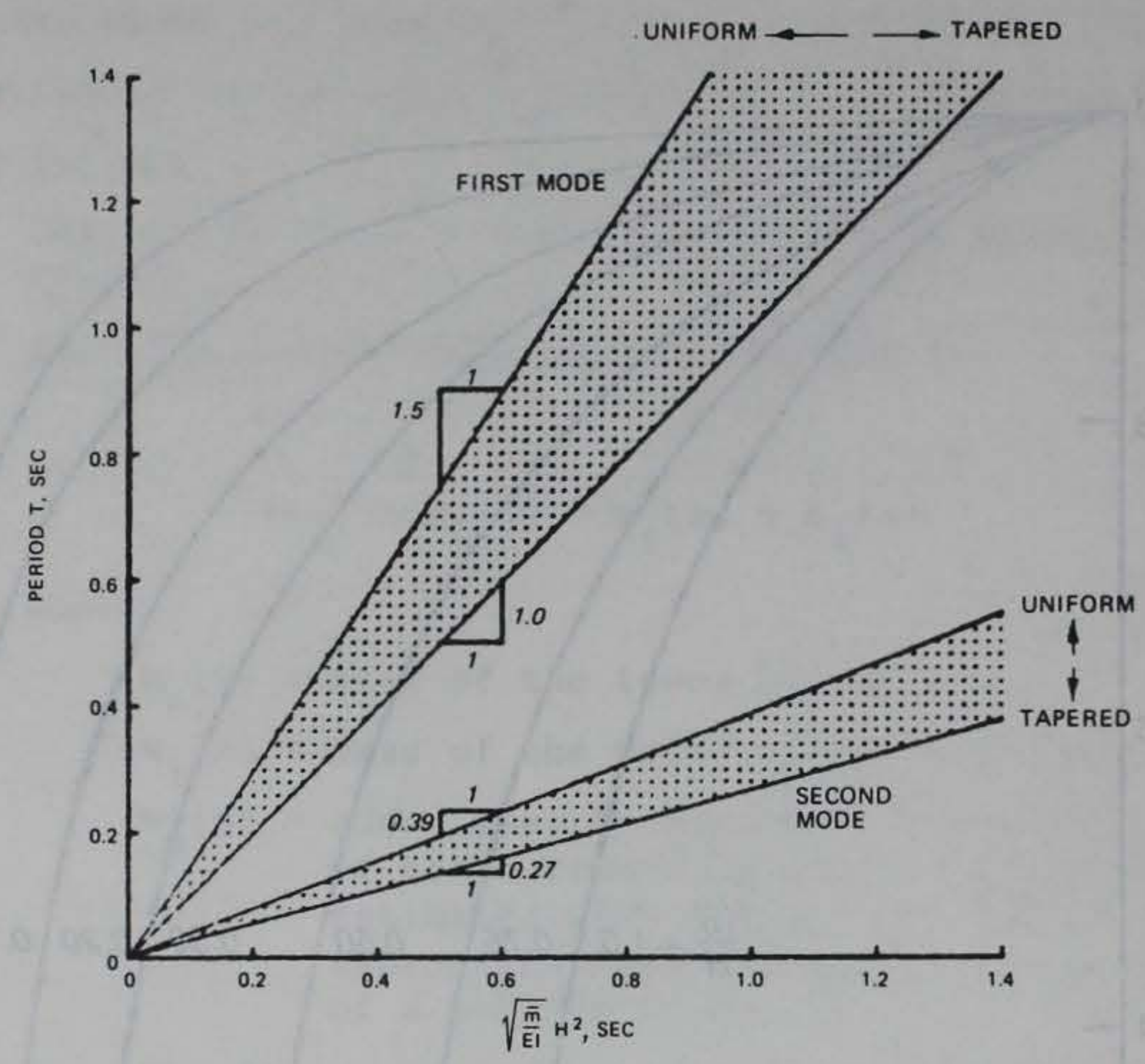

Figure 15. Approximate natural periods of intake towers

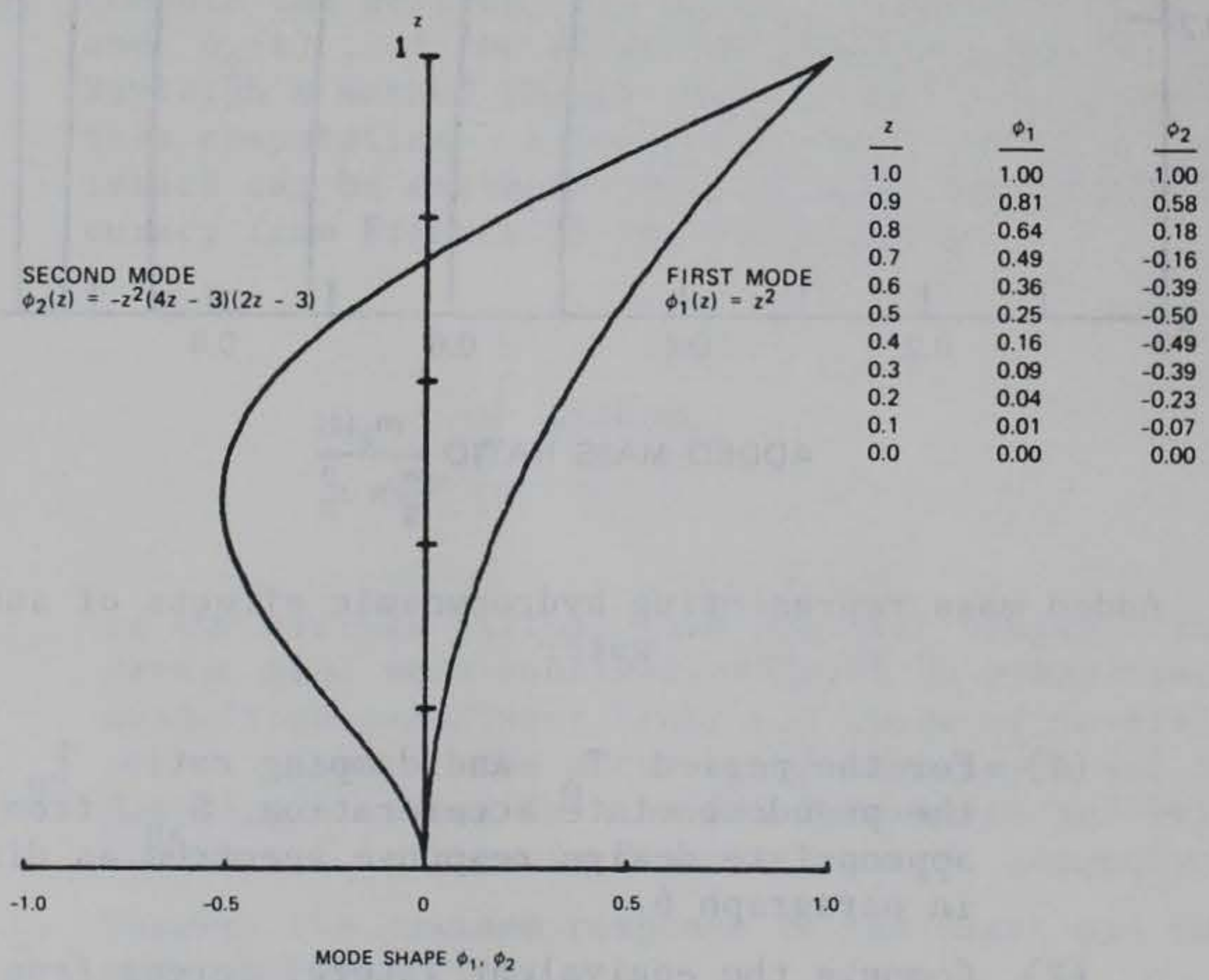

Figure 16. Approximate mode shapes of intake towers 
where

$$
f_{n}(z)=\frac{L_{n}}{M_{n}} S_{a n} m(z) \phi_{n}(z)
$$

$$
\begin{aligned}
& L_{n}=\int_{0}^{H} m(z) \phi_{n}(z) d z \\
& M_{n}=\int_{0}^{H} m(z) \phi_{n}^{2}(z) d z, n=1,2
\end{aligned}
$$

(3) Compute the internal forces (shears and moments) at any cross section by a static analysis of the tower subjected to the equivalent lateral forces:

$$
\begin{gathered}
V_{n}(z)=\int_{z}^{H} f_{n}(\zeta) d(\zeta) \\
M_{n}(z)=\int_{z}^{H} f_{n}(\zeta)(\zeta-z) d(\zeta), n=1,2
\end{gathered}
$$

where $\mathrm{z} \leq \zeta \leq \mathrm{H}$

d. Estimate the probable maximum shear $V(z)$ and moment $M(z)$ at any cross section by combining the modal maxima $V_{n}(z)$ and $M_{n}(z)$ in accordance with the root mean square equations of Clough and Penzien (1975):

$$
\begin{aligned}
& V(z) \approx \sqrt{V_{1}^{2}(z)+V_{2}^{2}(z)} \\
& M(z):=\sqrt{M_{1}^{2}(z)+M_{2}^{2}(z)}
\end{aligned}
$$

11. In Figures 8-13, the results of analyzing four different tower-earthquake permutations by this two-modal approximation procedure are presented. The accuracy of the procedure, when viewed in the context of the previously discussed refined analysis, may be adequate for preliminary design evaluation. However, the approximation of hydrodynamic effects by the same inertial mass in both modes of vibration 
and the effects of tower nonuniformity should be examined further before this observation is accepted as a general conclusion. For towers in which the seismic stresses predicted by the method are small compared to frequently anticipated stresses, this analysis may be all that is required for final design evaluation as well. The steps of this approximate procedure for a particular tower-earthquake combination are illustratively detailed in Appendix A.

Montes-Rosenblueth analysis

12. The seismically induced shear and moment distribution for intake towers can be estimated even more simply, but often somewhat more conservatively, by an adaptation (Chopra 1981) of a procedure proposed for chimney stacks (Montes and Rosenblueth 1968). The simple expressions for these distributions were developed from an analysis of a uniform flexural cantilever beam excited by idealized random support motions. The procedure starts with an estimate of the fundamental period $\mathrm{T}_{1}$ of the intake tower including the mass of the water inside and the virtual mass of the surrounding fluid. Next, shears and moments associated with a flat response spectrum, which bounds the design response spectrum as shown in Figure 17, are computed from:

$$
\begin{aligned}
& V(z)=0.647\left(\frac{\widetilde{S}_{a l}}{g}\right) W\left[1-\left(\frac{Z}{H}\right)^{3}\right] \\
& M(z)=0.461\left(\frac{\widetilde{S}_{a l}}{g}\right) \text { WH }\left(1-\frac{Z}{H}\right)^{3 / 2}
\end{aligned}
$$

where

$$
\begin{aligned}
\widetilde{\mathrm{S}}_{\mathrm{a} 1} & =\max \left[\mathrm{S}_{\mathrm{a}}(\mathrm{T})\right] \\
\mathrm{T} & \leq \mathrm{T}_{1} \\
\mathrm{~W} & =\text { total weight }=\mathrm{g} \int_{0}^{\mathrm{H}} \mathrm{m}(\mathrm{z}) \mathrm{dz}
\end{aligned}
$$

Additionally, shears and moments associated with a bounding hyperbolic spectrum having a low period cutoff as shown in Figure 17 are calculated from 


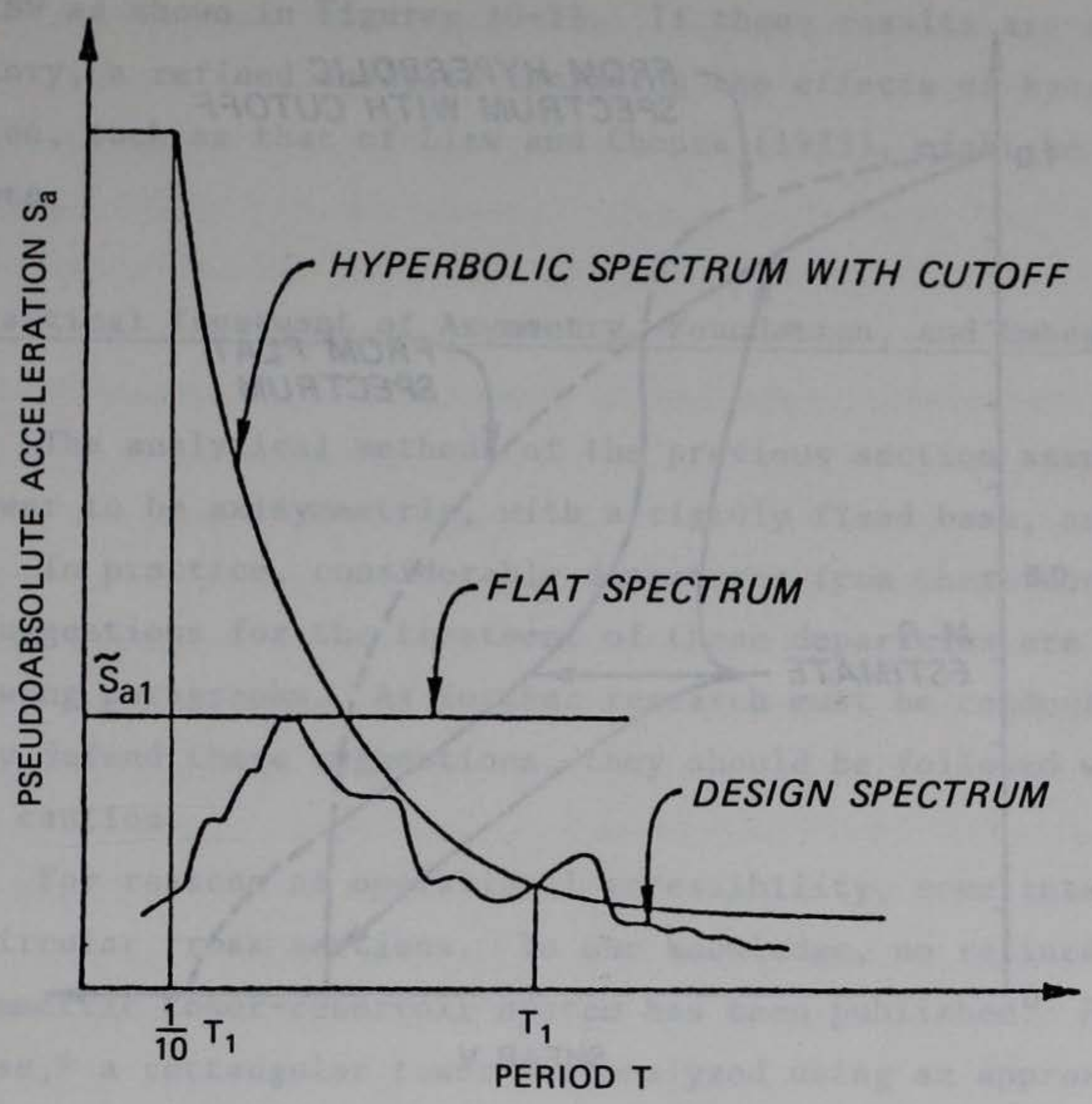

Figure 17. Envelopes of design spectrum

$$
\begin{aligned}
& V(z)=1.553\left(\frac{S_{a l}}{g}\right) W\left[\sqrt{1-\left(\frac{z}{H}\right)^{2}}-6.25\left(\frac{z}{H}\right)^{2}\left(1-\frac{z}{H}\right)^{2}\right] \\
& M(z)=0.519\left(\frac{S_{a l}}{g}\right) \text { WH }\left(1-\frac{z}{H}\right)
\end{aligned}
$$

Since, these two idealized spectra envelop the design spectrum, appropriate values of shear and moment at every elevation are provided by the minimum of the two values as shown for the values of shear in Figure 18. The results of analyzing four different tower-earthquake cases by this procedure are shown in Figures 8-13. The procedure can be seen to be quite conservative on occasion compared to the previously discussed two-mode and finite element methods. However, the procedure is considerably simpler to apply than the others as can be observed 


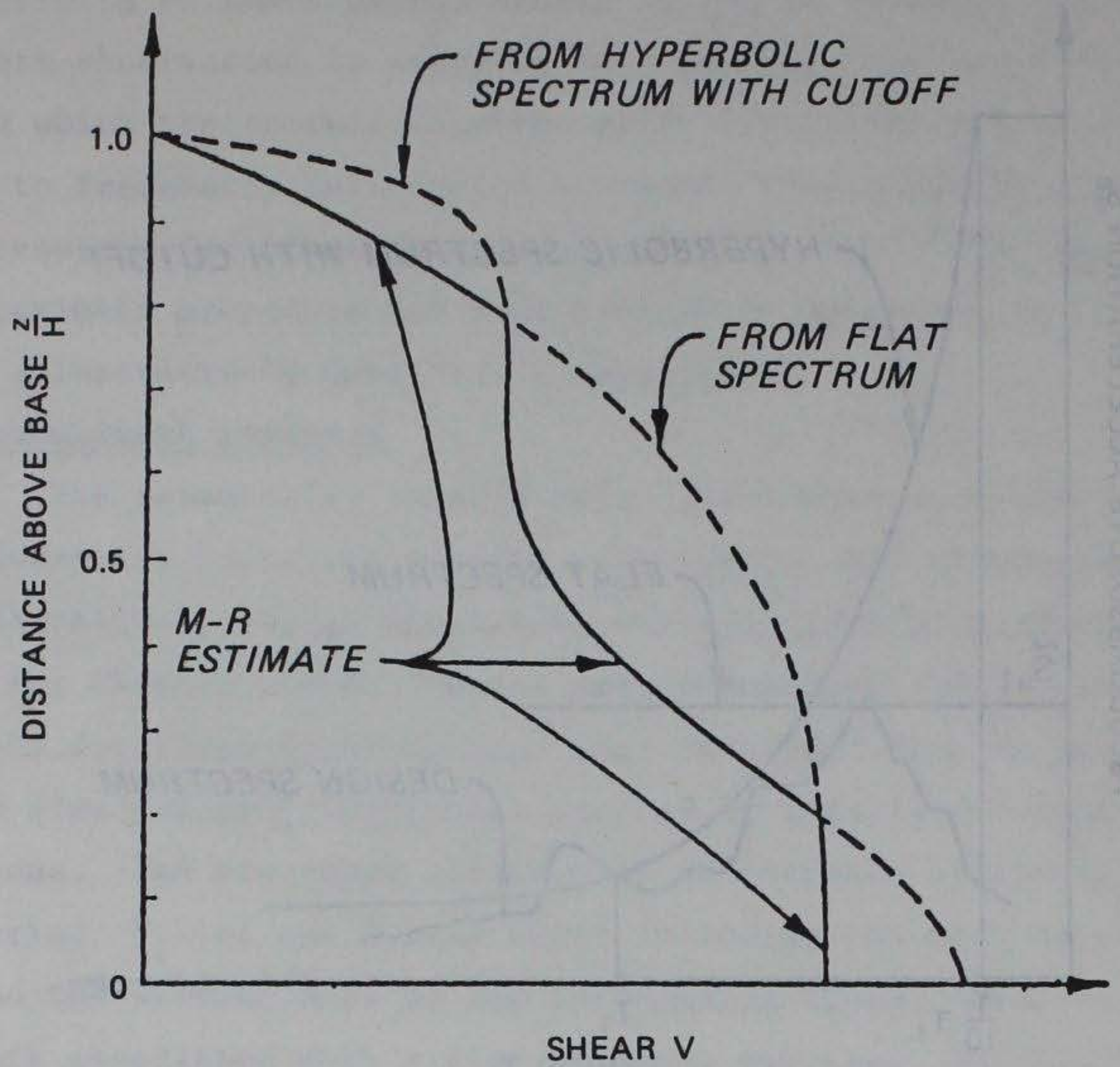

Figure 18. Explanatory sketch to obtain the MontesRosenblueth (M-R) estimate of shears

from the sample calculations for a particular tower-earthquake combination detailed in Appendix B.

Sequence of analyses

13. Thus, in an evaluation of the seismic safety of a tower design or an existing structure, the Montes-Rosenblueth procedure might be used for a first analysis since it is simple and conservative. If the results are satisfactory, the analysis need not be carried further. However, if the results are unacceptable, the additional work required to perform the more accurate two-mode added mass analysis might then be warranted. While the two-mode added mass analysis gives shears and moments closer to those obtained by the refined analysis using the EATSW computer program than the Montes-Rosenblueth method, the two-mode analysis may not always be more conservative than the refined analysis 
using EATSW as shown in Figures 10-13. If these results are also unsatisfactory, a refined analysis including the effects of hydrodynamic interaction, such as that of Liaw and Chopra (1973), might be appropriate.

\section{Practical Treatment of Asymmetry, Foundation, and Embedment}

14. The analytical methods of the previous section assumed the intake tower to be axisymmetric, with a rigidly fixed base, and freestanding. In practice, considerable departures from these conditions occur. Suggestions for the treatment of these departures are given in the following paragraphs. As further research must be conducted to rationally defend these suggestions, they should be followed with considerable caution.

15. For reasons of operational accessibility, some intake towers have noncircular cross sections. To our knowledge, no refined analysis of an asymmetric tower-reservoir system has been published. However, in one case,* a rectangular tower was analyzed using an approximate axisymmetric modal method with a slight modification. The modification replaced each rectangular cross section with an equal outer area circular one to calculate only the added mass representing the hydrodynamic interaction. In the remainder of this modal analysis, the properties of the actual rectangular cross section were used. The appropriateness of this modification remains to be evaluated through a more refined analysis.

16. Of course, no intake tower base is absolutely restrained, and the interaction among an intake tower, its reservoir, and its foundation remains a viable topic for future research. Practically speaking, from the results of similar research for dams (Chopra, Chakrabarti, and Gupta 1980), it is expected that, if the foundation

* P. F. Mlakar, "Preliminary Seismic Analysis of Cerillos Tower," Letter Report submitted to the U. S. Army Engineer District, Jacksonville, from the U. S. Army Engineer Waterways Experiment Station, Vicksburg, Miss., 1979. 
stiffness is not large relative to the tower stiffness, the tower's natural periods will be longer than those computed by the fixed-base methods. This can increase or decrease the dynamic response depending on the period characteristics of the site's design earthquake. This effect should be qualitatively assessed in comparing the fixedbase internal forces with the criteria discussed in the next section.

17. Sometimes, intake towers are partially embedded in an earth dam. Recently, the effects of the partial embedment of a specific structure were examined with a rather sophisticated nonlinear soilstructure interaction analytical procedure.* A thorough parametric investigation of the seismic behavior of such structural systems is yet to be performed. However, in some such situations, it may be possible to simply and conservatively ignore the presence of the surrounding earth and ensure the seismic safety through the free-standing methods of the previous section. If these results are unacceptable, the free-standing methods might be modified to include an equivalent linearly elastic restraint along the spatial extent of partial embedment.

\section{Criteria}

18. Once the distributions of seismically induced shear and moment have been determined by any of the foregoing preliminary or refined procedures, these distributions should be compared to the capacity of the intake tower cross sections. In this comparison, the stresses from the static loads should be combined with the stresses from the earthquake loading. The loading cases, including earthquake, to be examined are contained in paragraph 3-07, page 26, of Engineer Manual (EM) 1110-2-2400 (Office, Chief of Engineers 1964). The strength design criteria for determining the structural capacity of the intake tower are contained in Engineer Technical Letter (ETL) 1110-2-265

* Civil Systems Incorporated, "Dynamic Analysis of Structures of Isabella Dams, Kern County, California," Report to the U. S. Army Engineer District, Sacramento, Calif. 
(Office, Chief of Engineers 1981). An example of the strength design of an intake tower is contained in the report by Liu 1980. The criteria for the stability of the tower are also contained in paragraph 3-07 of EM 1110-2-2400, except of the following: the seismic coefficients for the overturning and sliding stability in paragraph 3-07 have been superseded by those listed in Engineer Regulation (ER) 1110-2-1806 (Office, Chief of Engineers 1977) and the current sliding analysis criteria are contained in ETL 1110-2-256 (Office, Chief of Engineers 1981).

19. The elastic structural response implied by the above criteria seems appropriate for those intake towers which are critically important; i.e., in those cases where the tower would be needed for a controlled release of the reservoir to repair any seismic damage in the damming structure. The high cost associated with these criteria for a noncritical tower loaded by a credible but extremely unlikely large earthquake suggests the possibility of inelastic criteria for such structures. However, there presently exists insufficient information about the ductility of intake towers on which to establish generally applicable inelastic criteria. Thus, any relaxation of the criteria cited in the preceding paragraph would have to be justified on a case-by-case base.

\section{Additional Research Needed}

20. As mentioned in the foregoing, further research is needed to analyze the seismic behavior of intake towers. Only rather modest efforts would be required to examine:

a. The effects of nonuniformity on the added mass representation of hydrodynamic interaction in Figure 14 .

b. The effect of representing second-mode hydrodynamic interaction by the first-mode added mass approximation in Figure 14.

c. The effect of assuming contained water to move rigidly with the structure. 
d. The effect of approximating modal characteristics with the standard shapes in Figures 15 and 16.

e. The conditions under which one, two, or more modes of vibration are adequate to estimate response.

21. More extensive studies are necessary to establish the effects of:

a. Asymmetry on hydrodynamic interaction.

b. Three-dimensional excitation on response.

c. Foundation flexibility on behavior.

d. Structure embedment in an earth embankment on response.

e. Inelastic behavior on design forces.

\section{$\underline{\text { Summary }}$}

22. Dynamic methods of analysis have been discussed which more rationally represent the seismic response of free-standing, fixed-base intake tower reservoir systems than the seismic coefficient method. As these methods explicitly include only the most important effects, they should be used cautiously in practice. Further investigations are warranted to adequately quantify the influence of simplifying assumptions made in such analyses. 


\section{References}

Biggs, J. M. 1964. Structural Dynamics, McGraw-Hill, New York.

Chopra, A. K., Chakrabarti, P., and Gupta, S. 1980. "Earthquake Response of Concrete Gravity Dams Including Hydrodynamic and Foundation Interaction Effects," Report No. 80-01, Earthquake Engineering Research Center, University of California, Berkeley, Calif.

Clough, R. W. and Penzien, J. 1975. Dynamics of Structures, McGrawHill, New York.

Hays, W. W. 1980. "Procedures for Estimating Earthquake Ground Motions," Geological Survey Professional Paper No. 1114, U. S. Geological Survey, Washington, D. C.

Liaw, C-Y. and Chopra, A. K. 1973. "Earthquake Response of Axisymmetric Tower Structures Surrounded by Water," Report No. 73-25, Earthquake Engineering Research Center, University of California, Berkeley, Calif.

. 1975. "Earthquake Resistant Design of Intake-Outlet Towers," Journal of the Structural Division, American Society of Civil Engineers, Vol 101, No. ST7, pp 1349-1366.

Liu, T. C., 1980. "Strength Design of Reinforced Concrete Hydraulic Structures; Preliminary Strength Design Criteria," Technical Report SL-80-4, Report 1, U. S. Army Engineer Waterways Experiment Station, Vicksburg, Miss.

Montes, R. and Rosenblueth, E. 1968. "Cortantes y Momentos Sismicos En Chimeneas," Segundo Congreso Nacional de Ingenieria Sismica, Veracruz, Mexico.

Office, Chief of Engineers, Department of the Army. 1964. "Structural Design of Spillways and Outlet Works," Engineer Manual 1110-2-2400, Washington, D. C.

- 1977. "Earthquake Design and Analysis for Corps of Engineer Dams," Engineer Regulation 1110-2-1806, Washington, D. C.

. 1981. "Sliding Stability for Concrete Structures," Engineer Technical Letter 1110-2-256, Washington, D. C.

- 1981. "Strength Design Criteria for Reinforced Concrete Hydraulic Structures," Engineer Technical Letter 1110-2-265, Washington, D. C.

Rea, D., Liaw, C-Y., and Chopra, A. K. 1975. "Dynamic Properties of San Bernardino Intake Tower," Report No. 75-7, Earthquake Engineering Research Center, University of California, Berkeley, Calif. 
Appendix A: Two-Mode Added Mass Approximate Analysis of the

\section{San Bernardino Tower Excited by the Taft, Calif., Earthquake, 21 July 1952 (S69E Component)}

1. This appendix details a two-mode added mass approximate analysis of the San Bernardino tower excited by the S69E component of the 21 July 1952, Taft, Calif., earthquake.

2. The material properties of the San Bernardino Tower are assumed as follows:

a. Modulus of elasticity of concrete $=4.5$ million psi.

b. Modulus of elasticity of steel $=30$ million psi.

c. Poisson's ratio $=0.17$.

d. Unit weight $=155$ pcf.

e. Damping $=5$ percent of critical.

3. Figure $A 1$ and Table $A 1$ show the discretization of this structure for the computation of the natural periods, $\mathrm{T}_{1}, \mathrm{~T}_{2}$, and mode shapes, $\phi_{1}, \phi_{2}$. These were computed using a Tektronix 4051 BASIC minicomputer program for a nonuniform cantilever beam analysis. The interactive input-output is presented on pages $\mathrm{A} 4-\mathrm{A} 13$, while the source listing is given on pages A14-A19. 


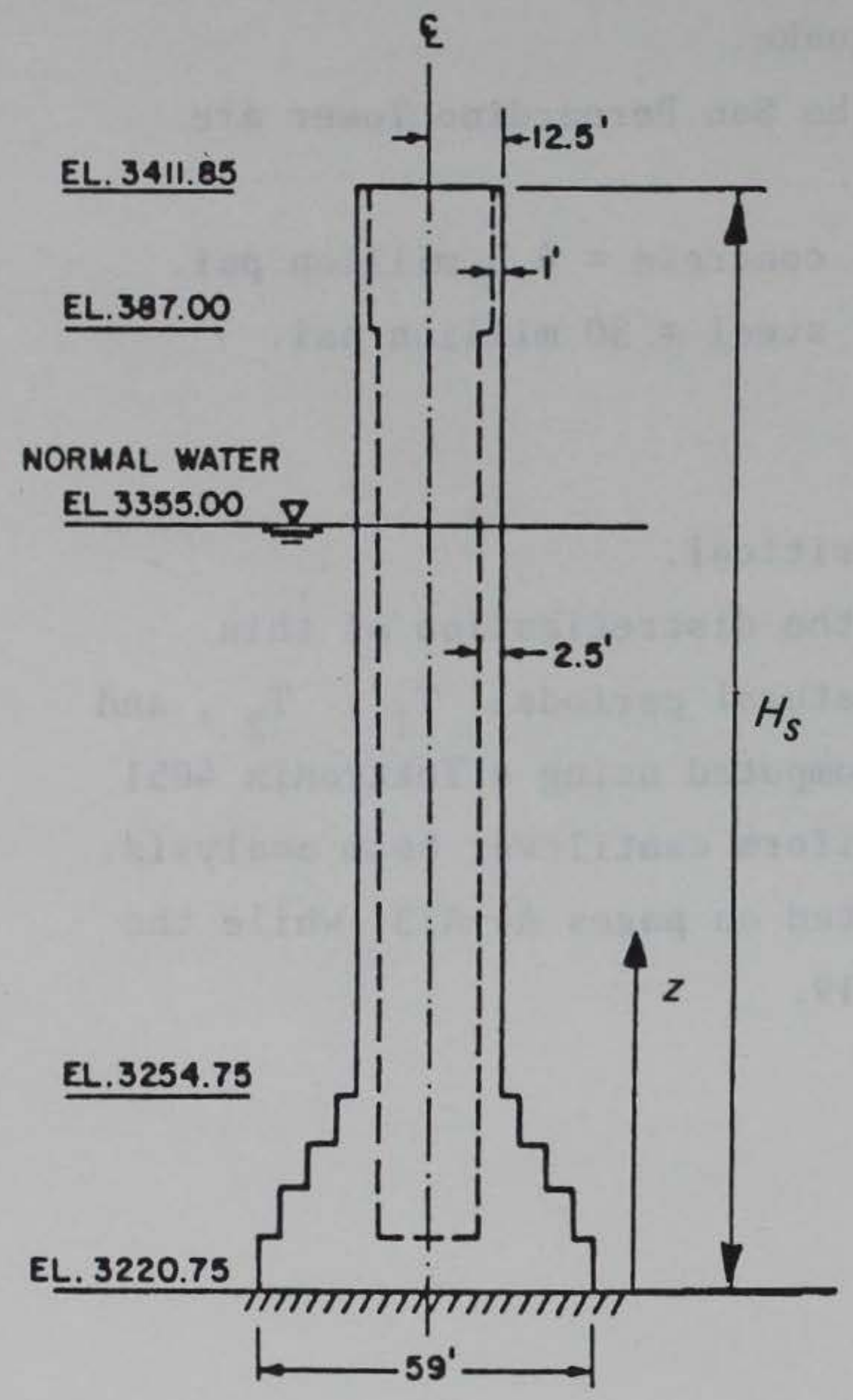

a. SAN BERNARDINO TOWER

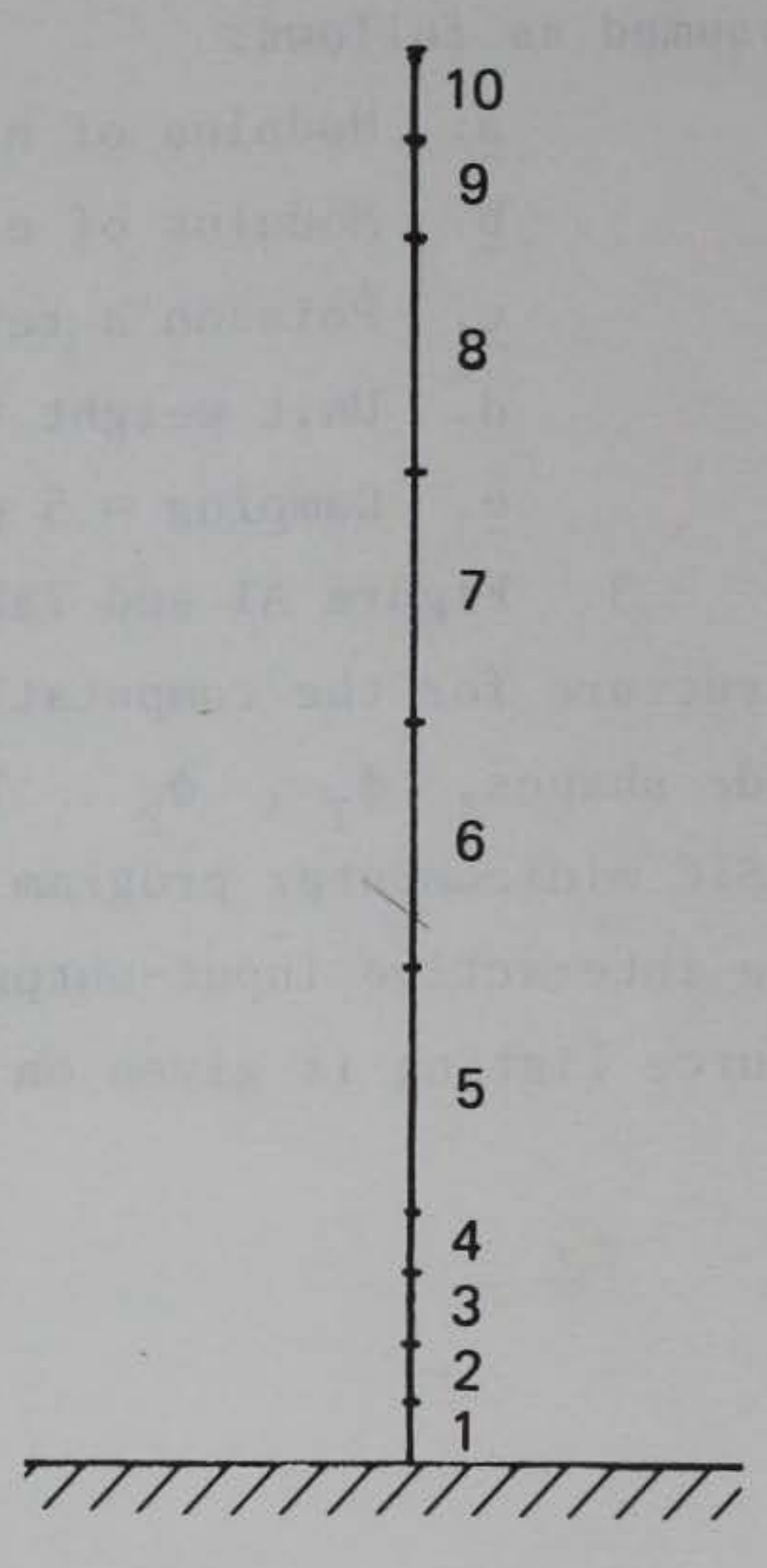

b. RAYLEIGH METHOD GRID

Figure A1. Discretization of the San Bernardino tower for the Rayleigh's method calculation 
Table Al

Structural Properties of the San Bernardino Tower

\begin{tabular}{|c|c|c|c|}
\hline & Length & Mass & Stiffness \\
\hline Section & in. & $\underline{1 b-\sec ^{2} / i n .}$ & $10^{15} \mathrm{lb}-\mathrm{in} .^{2}$ \\
\hline 1 & 102.00 & $12,778.0$ & 55.50 \\
\hline 2 & 102.00 & $8,752.0$ & 29.06 \\
\hline 3 & 102.00 & $5,891.1$ & 13.52 \\
\hline 4 & 102.00 & $3,537.7$ & 5.036 \\
\hline 5 & 396.72 & $6,500.5$ & 1.073 \\
\hline 6 & 396.72 & $6,410.7$ & 1.073 \\
\hline 7 & 409.56 & $5,526.4$ & 1.073 \\
\hline 8 & 384.00 & $1,980.8$ & 1.073 \\
\hline 9 & 149.16 & 374.9 & 0.50824 \\
\hline 10 & 149.04 & 374.6 & 0.50824 \\
\hline Total & 2293.20 & $52,126.7$ & \\
\hline
\end{tabular}


FIRST AND SECOND FRENQUENCIES OF NON-UNIFORM

CANTILEUER USING RAYLEIGH'S METHOD

ENTER NUMBER OF SECTIONS

$=18$

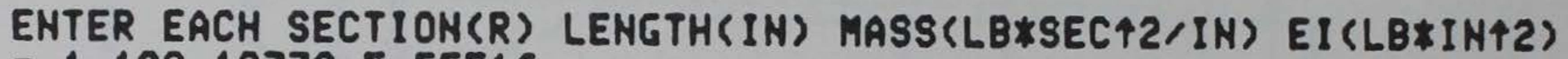

$=1,102,12778,5.55 E 16$

$=2,182,8752,2.906 E 16$

$=3,182,5891.1,1.352 E 16$

$=4,182,3537.7,5.836 E 15$

$=5,396.72,6580.5,1.073 E 15$

$=6,396.72,6410.7,1.073 E 15$

$=7,499.56,5526.4,1.873 E 15$

$=8,384,1980.8,1.073 E 15$

$=9,149.16,374.9,5.0824 E 14$

$=10,149.04,374.6,5.0824 E 14$

ENTER ASSUMED SHAPE (PHIP(1),..PPIP(J))

$=0.1$

$=0.2$

$=0.3$

$=0.4$

$=0.5$

$=0.6$

$=0.7$

$=0.8$

$=0.9$

$=1.0$ 


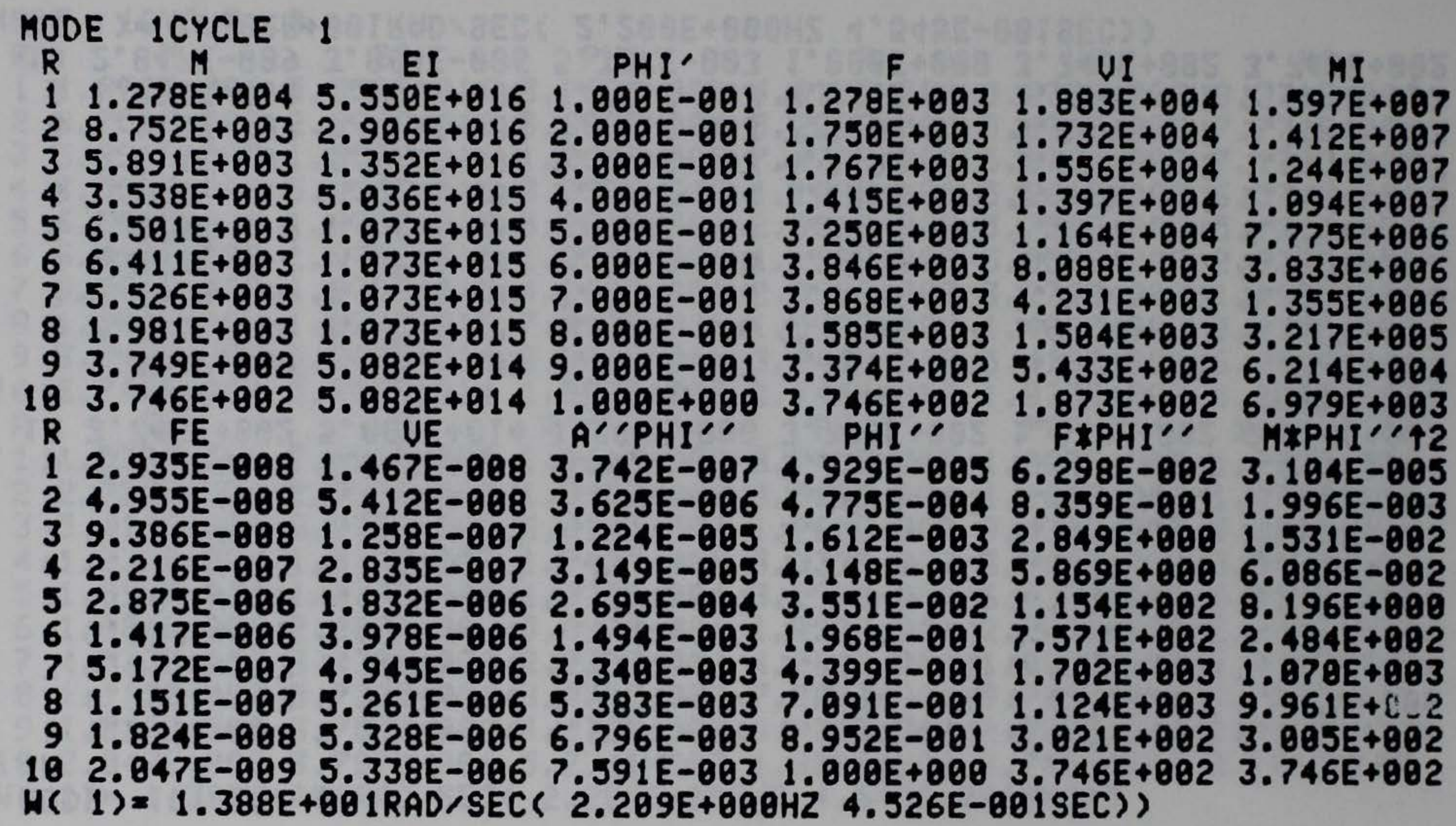


MODE 1CYCLE 2

$\begin{array}{ll}R & M \\ 1 & 1.278 E+0045\end{array}$

$28.752 E+803$

$35.891 E+083$

. $50 E+016$

EI

PHI'

$F$

$6.298 E-001$

UI

$4.929 E-005$

$4.179 E+000$

$6.067 E+003$

$6.065 E+003$

1. $612 \mathrm{E}-003$

$43.538 E+883$

1. $352 E+816$

$4.148 E-003$

$9.497 E+800$

$6.058 E+003$

$56.581 E+803$

$5.036 E+015$

$3.551 E-802$

1. $467 E+081$

$6.046 E+003$

$2.308 E+002$

$5.923 E+003$

$1.873 E+815$

1.968E-001

$5.526 E+B \theta 3$

$1.073 E+015$

$81.981 E+003$

$1.073 E+015$

4.399E-001

$1.262 E+803$

$5.177 E+003$

7.091E-001

$2.431 E+003$

$3.330 E+003$

1. $405 E+003$

$1.413 E+003$

$103.746 E+8025.882 E+814$

$8.952 E-001$

$\mathbf{R}$ FE

UE

$3.356 E+802$

$5.424 E+002$

$1.000 E+000$ A'PHI'

PHI'

$1.873 E+002$ F\$PHI'

8. $\begin{gathered}M I \\ \text { II }\end{gathered}$

$7.963 E+006$

$7.344 E+006$

$1 \quad 1.577 E-0087.886 E-0092.011 E-007$

$22.795 E-088$

$35.541 E-008$

2. $975 E-808$

$1.965 E-806$

3. $768 E-005$

2.373E-005

$6.727 E+006$

5. $233 E+006$

$41.363 E-007$

7. 143E-008

6.775E-086

1. $673 E-007$

$1.792 E-805$

$3.682 E-004$

$1.539 E-803$

2. $980 E+806$

$1.935 E-006$

$1.203 E-006$

$1.798 E-604$

$1.2695-803$

$1.206 E-002$

$3.357 E-003$

$4.926 E-002$

$1.209 E+006$

6 1. 102E-906

2.721E-006

9.904E-004

$3.201 E-002$

$7.387 E+000$

$3.126 E+805$

$74.614 E-007$

3. 502E-006

$2.278 E-603$

$91.823 \mathrm{E}-988$

$3.789 E-006$

$3.741 E-603$

$4.269 E-081$

$2.342 E+002$

$6.211 E+084$

18 2.847E-009

$3.854 E-806$

$4.761 E-803$

?.010E-001

$1.638 E+003$

$9.847 E+682$

$2.994 E+802$

8.921E-001

3. $746 E+802$

$6.979 E+003$

M*PHI 42

$1.814 E-005$

$1.187 E-603$

H( 1$)=1.382 E+081$ RAD $/$ SEC

$3.337 \mathrm{E}-003$

$9.493 E-803$

$3.987 E-002$

$6.659 E+808$

$2.208 E+602$

1. $087 E+003$

$9.734 E+802$

$2.984 E+002$

$3.746 E+802$ (2 4.545E-001SEC) 
MODE ICYCLE 3

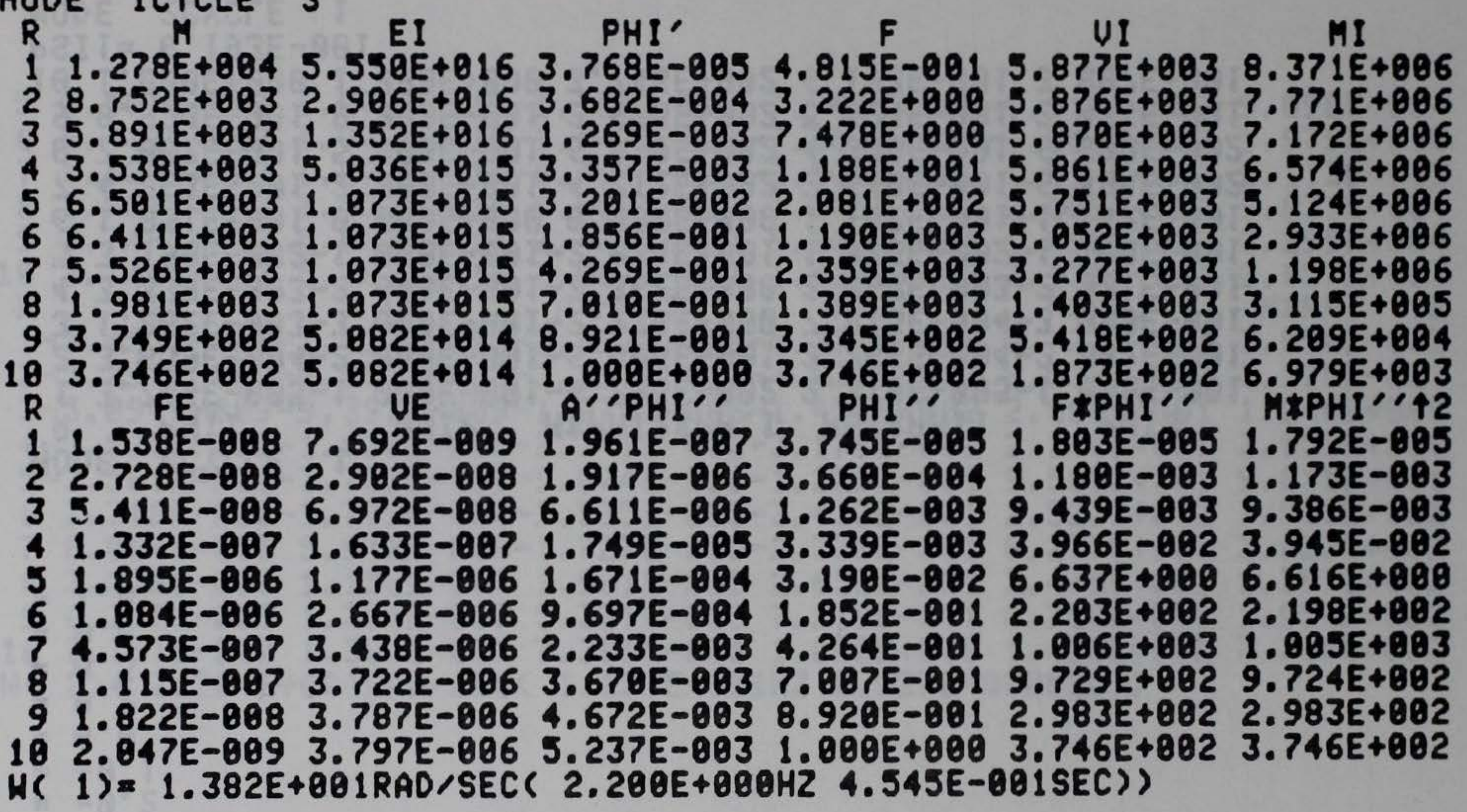


ENTER ASSUMED SHAPE (PHIP $(1), \ldots P H I P(J))$

$$
\begin{aligned}
& =-0.1 \\
& =-0.2 \\
& =-0.3 \\
& =-8.2 \\
& =-8.1 \\
& =0.8 \\
& =0.2 \\
& =0.5 \\
& =0.8 \\
& =1.0
\end{aligned}
$$

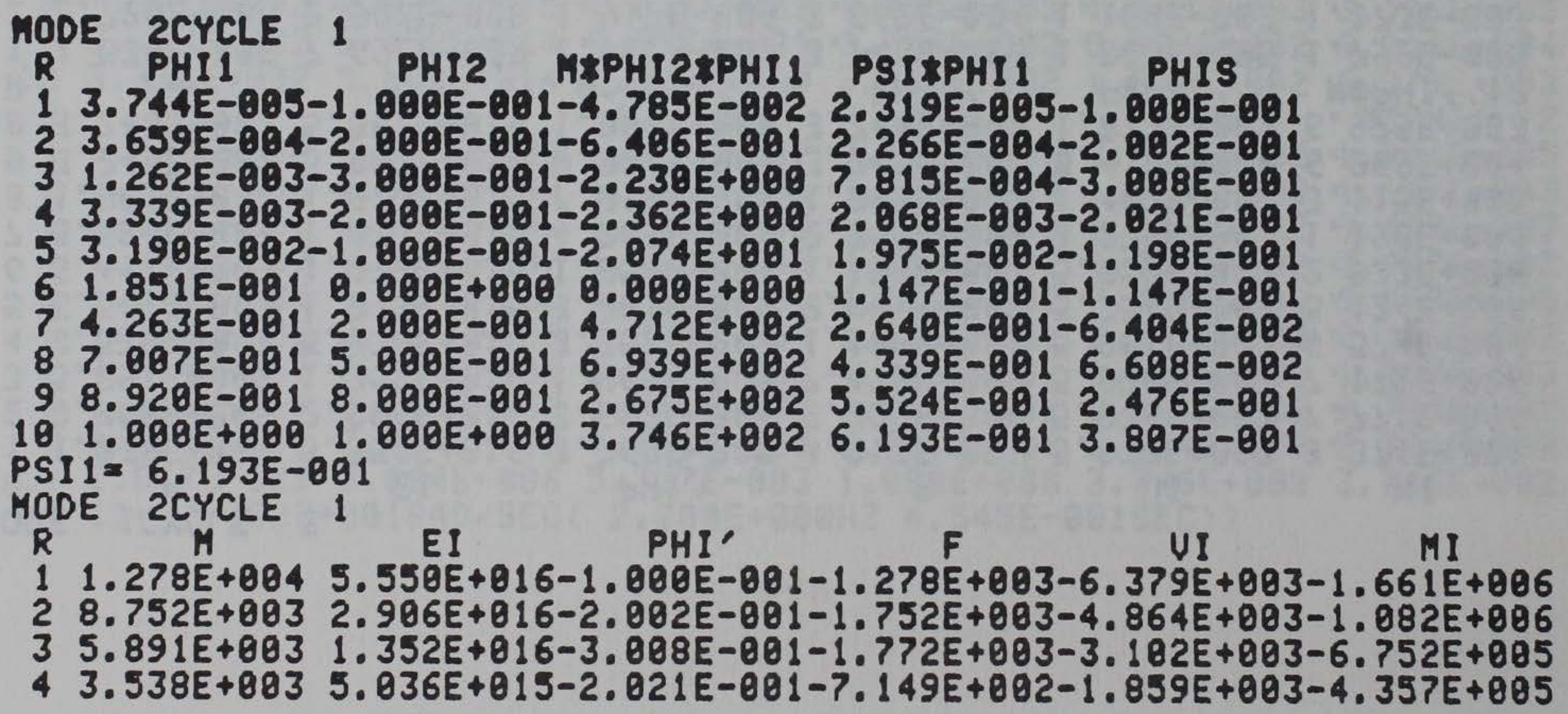


$56.501 E+0831.873 E+815-1.198 E-001-7.785 E+002-1.112 E+003-9.090 E+084$

$66.411 E+0031.073 E+015-1.147 E-081-7.351 E+002-3.551 E+0021.979 E+005$

$75.526 E+0031.073 E+015-6.404 E-002-3.539 E+002 \quad 1.894 E+0022.113 E+005$

$81.981 E+003 \quad 1.073 E+015 \quad 6.608 E-002 \quad 1.309 E+002 \quad 3.809 E+002 \quad 9.031 E+084$

$93.749 E+0025.082 E+0142.476 E-0019.282 E+001 \quad 1.890 E+002 \quad 2.299 E+004$

$103.746 E+0825.882 E+014 \quad 3.807 E-001 \quad 1.426 E+002 \quad 7.130 E+001 \quad 2.657 E+003$

$R$ FE UE APHI", PHI" F*PHI", MAPHI" 42

$1-3.053 E-009-1.527 E-009-3.893 E-008-5.271 E-0046.737 E-0013.550 E-003$

$2-3.797 E-089-4.951 E-009-3.598 E-007-4.872 E-003 \quad 8.538 E+080 \quad 2.078 E-001$

$3-5.094 E-009-9.397 E-009-1.075 E-086-1.456 E-002 \quad 2.580 E+8011.248 E+008$

$4-8.825 E-009-1.636 E-008-2.341 E-006-3.170 E-002 \quad 2.266 E+001 \quad 3.555 E+000$

$5-3.361 E-008-3.757 E-008-9.074 E-006-1.229 E-0019.565 E+0019.815 E+801$

$67.318 E-008-1.779 E-088-2.535 E-085-3.433 E-0012.523 E+002 \quad 7.555 E+002$

$78.064 E-008$ 5.912E-008-1.727E-005-2.339E-001 8.277E+001 3.023E+002

$83.232 E-008$ 1.156E-007 $1.961 E-005$ 2.655E-001 3.476E+001 $1.397 E+002$

$96.748 E-0091.351 E-007 \quad 5.331 E-005$ 7.219E-001 $6.700 E+001 \quad 1.954 E+002$

$107.791 E-0101.389 E-0077.385 E-0051.000 E+0001.426 E+0023.746 E+002$

H( 2$)=7.284 E+801 R A D / S E C(1.159 E+001 \mathrm{H} 28.627 E-002 S E C)$ ) 


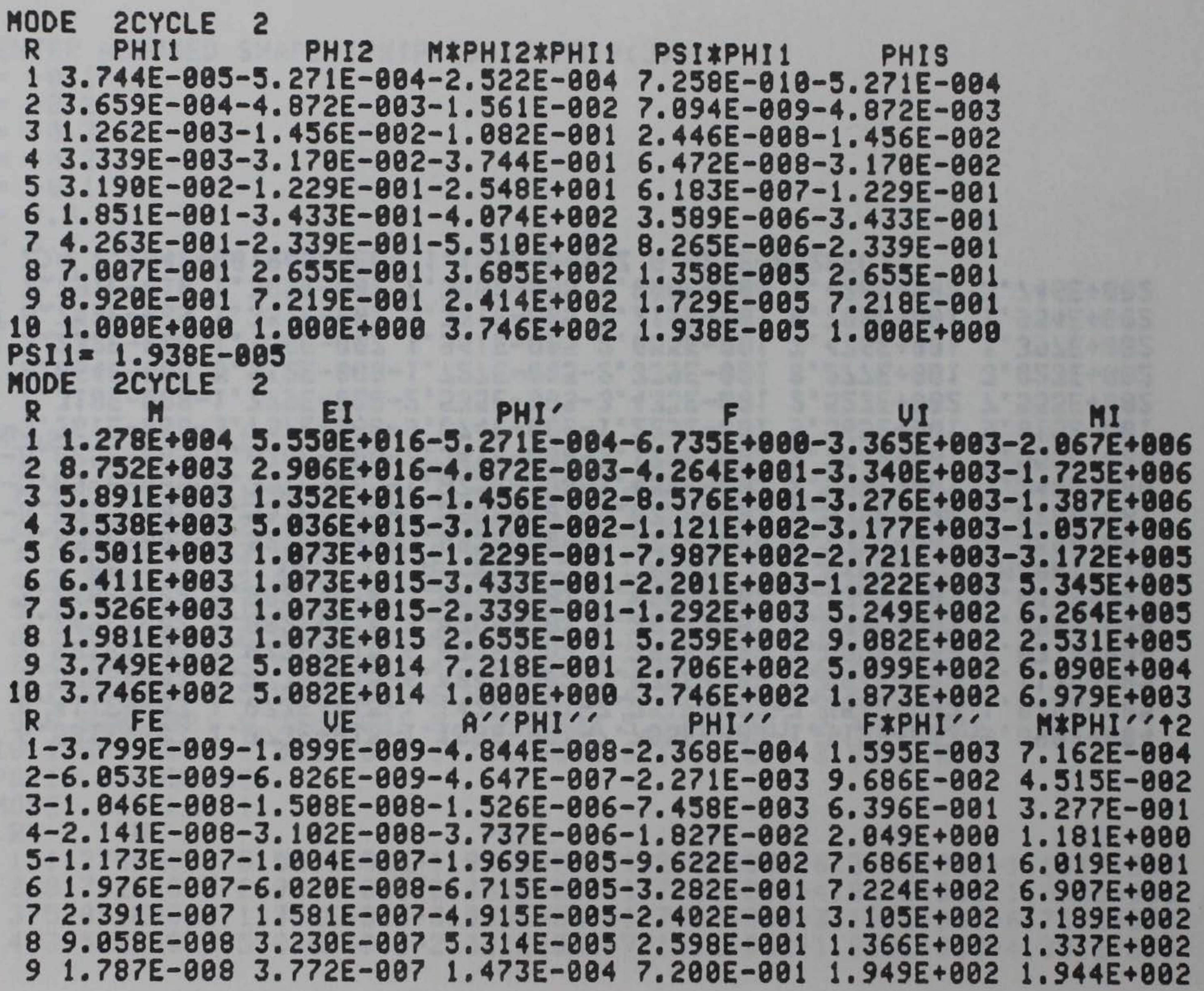


$10 \quad 2.046 E-809 \quad 3.872 E-807 \quad 2.046 E-004 \quad 1.080 E+080 \quad 3.746 E+002 \quad 3.746 E+002$ $H(2)=7.079 E+\theta 01 R A D / S E C(1.127 E+001 H Z 8.876 E-002 S E C))$

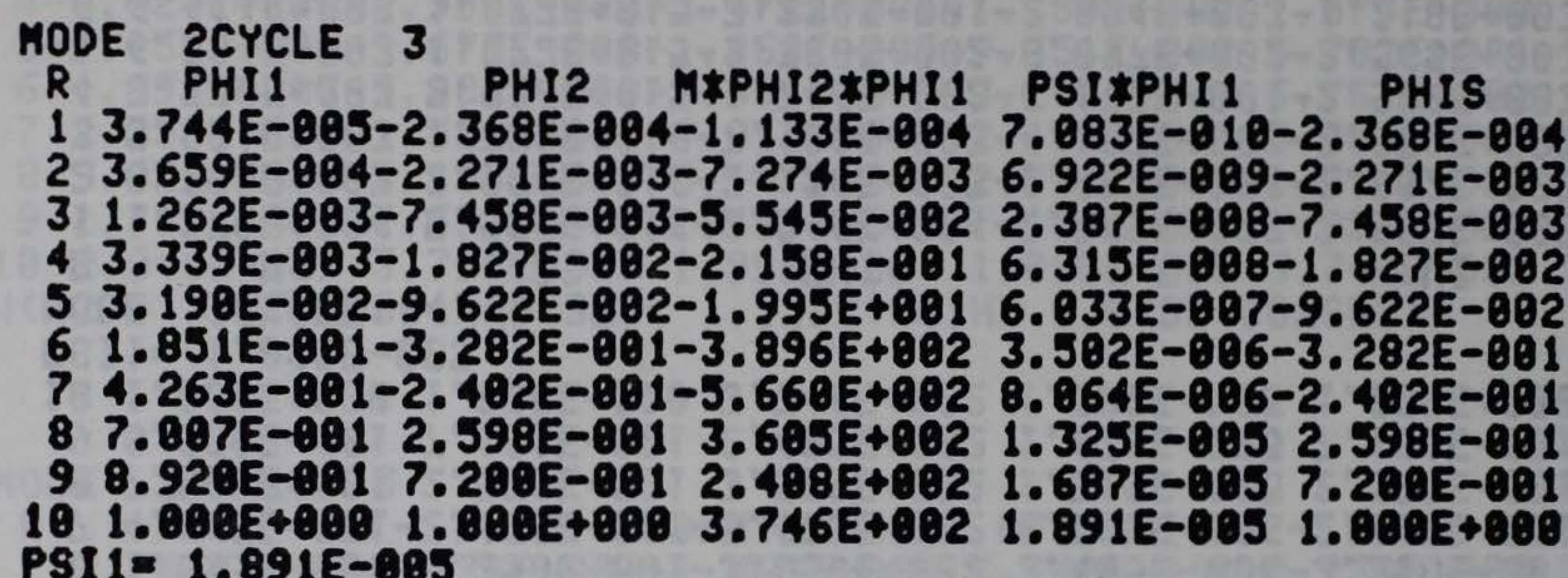

MODE 2CYCLE 3

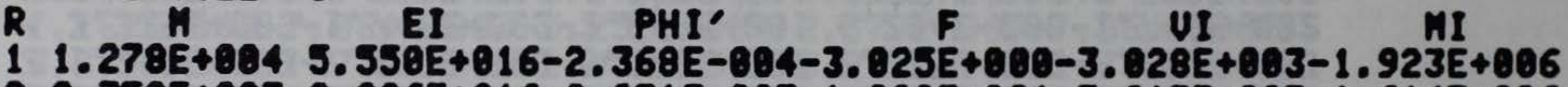

$28.752 E+0032.986 E+816-2.271 E-003-1.989 E+001-3.017 E+003-1.614 E+006$

$35.891 E+0031.352 E+816-7.458 E-003-4.394 E+081-2.985 E+003-1.308 E+006$

$43.538 E+0835.036 E+015-1.827 E-002-6.463 E+001-2.931 E+003-1.006 E+006$

$56.501 E+8031.073 E+015-9.622 E-002-6.255 E+002-2.586 E+003-3.131 E+005$

$66.411 E+8031.073 E+015-3.282 E-001-2.104 E+803-1.221 E+0035.152 E+805$

$75.526 E+0031.073 E+015-2.402 E-001-1.328 E+003 \quad 4.952 E+0026.196 E+005$

$81.981 E+0031.073 E+0152.598 E-0015.145 E+002 \quad 9.018 E+002 \quad 2.524 E+005$

$93.749 E+0025.082 E+0147.200 E-0012.699 E+0025.096 E+0026.088 E+004$

$183.746 E+8025.082 E+8141.000 E+8003.746 E+8021.873 E+802$

R

$1-3.533 E-009-1.767 E-009-4.505 E-008-2.246 E-0046.793 E-004$

2-5.665E-009-6.366E-809-4.326E-807-2.156E-003 4.287E-802

$3-9.865 E-009-1.413 E-008-1.424 E-006-7.100 E-0033.120 E-001$

$4-2.037 E-008-2.925 E-008-3.503 E-086-1.746 E-0821.128 E+\theta 00$

$6.979 E+003$

M*PHI 142

$6.443 E-004$

$4.078 E-802$

2.970E-801

1. $078 E+800$ 
$5-1.158 E-007-9.732 E-008-1.882 E-005-9.380 E-002$

$61.905 E-007-5.996 E-008-6.521 E-005-3.250 E-001$

$72.365 E-007$ 1.535E-007-4.832E-005-2. 409E-081

$89.832 E-808$

$91.787 \mathrm{E}-808$

\begin{tabular}{l}
$3.710 E-9 \theta 7$ \\
$3.810 E-8 \theta 7$ \\
\hline
\end{tabular}

$5.174 E-005$

2. $579 E-001$

$1.443 E-804$

$7.191 E-08$

2. $006 \mathrm{E}-00 \mathrm{e}$

$5.867 E+801$

$6.839 E+002$

$3.198 E+002$

$1.327 E+882$

$1.941 E+002$

$H(2)=7.077 E+001$ RAD $/$ SEC $(1.126 E+001 \mathrm{HZ} \quad 8.878 E-002 \mathrm{SEC})$ )
$5.719 E+001$

$6.772 E+802$

$3.206 E+802$

$1.318 E+802$

$1.939 E+802$

$3.746 E+882$

MODE 2CYCLE 4

R PHI1 PHI2 M\$PHI2\$PHI1

$23.659 E-084-2.156 E-003-6.907 E-003$

3 1.262E-003-7. 100E-003-5.278E-002

$43.339 E-003-1.746 E-802-2.062 E-001$

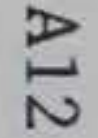

5 3.190E-082-9.380E-002-1.945E+001

$61.851 E-001-3.250 E-001-3.858 E+802$

? $4.263 E-001-2.409 E-001-5.675 E+002$

$87.097 E-0012.579 E-0013.579 E+002$

$98.920 E-801$ ?.191E-001 2.405E+802

$181.80 \theta E+\theta 001.008 E+\theta \theta 03.746 E+802$

PSI $1=1.882 E-005$

HODE 2CYCLE 4

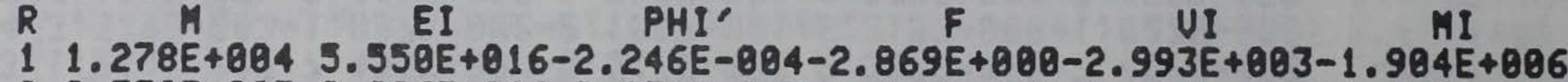

$28.752 E+8032.906 E+016-2.156 E-003-1.887 E+001-2.982 E+003-1.600 E+006$

$35.891 E+8031.352 E+016-7.100 E-003-4.183 E+001-2.952 E+003-1.297 E+006$

$43.538 E+0035.036 E+015-1.746 E-002-6.177 E+001-2.900 E+003-9.979 E+805$

$56.501 E+0031.073 E+015-9.380 E-002-6.097 E+002-2.565 E+003-3.118 E+805$

$66.411 E+8031.073 E+015-3.250 E-001-2.084 E+\theta 03-1.218 E+0035.116 E+\theta 05$

$75.526 E+8031.073 E+015-2.409 E-801-1.331 E+003 \quad 4.895 E+002 \quad 6.177 E+005$

$81.981 E+0031.073 E+0152.579 E-001 \quad 5.108 E+002 \quad 8.996 E+002 \quad 2.521 E+005$

$93.749 E+\theta 02 \quad 5.082 E+014 \quad 7.191 E-001 \quad 2.696 E+002 \quad 5.094 E+\theta 02 \quad 6.088 E+\theta 04$

$103.746 E+8025.082 E+014 \quad 1.800 E+000 \quad 3.746 E+002 \quad 1.873 E+\theta 02 \quad 6.979 E+\theta 03$ 


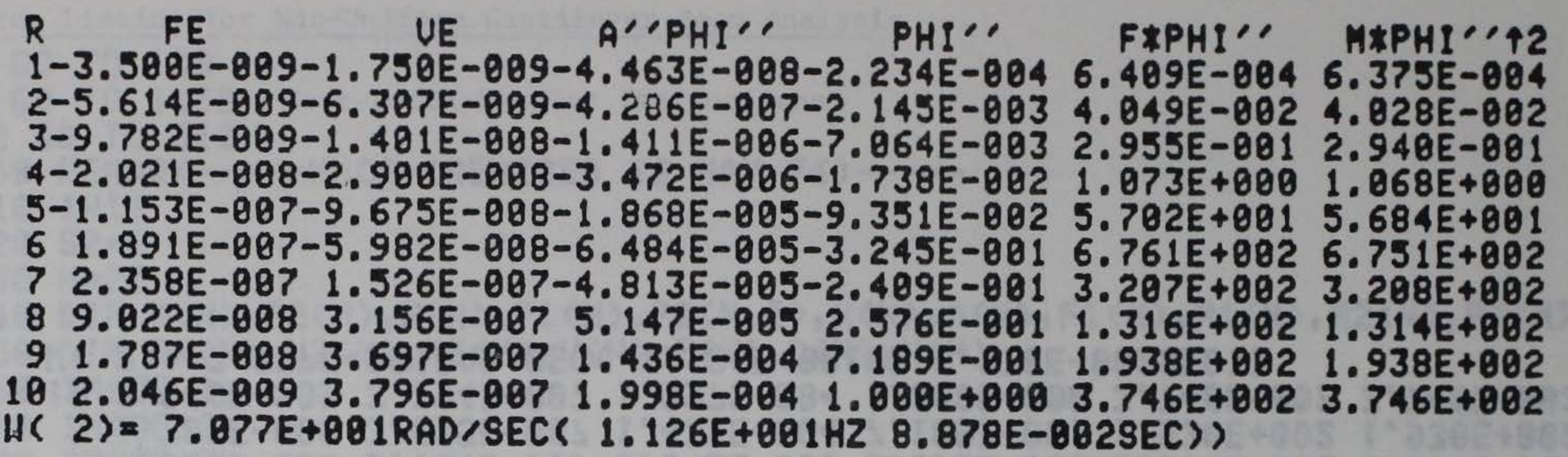

岕

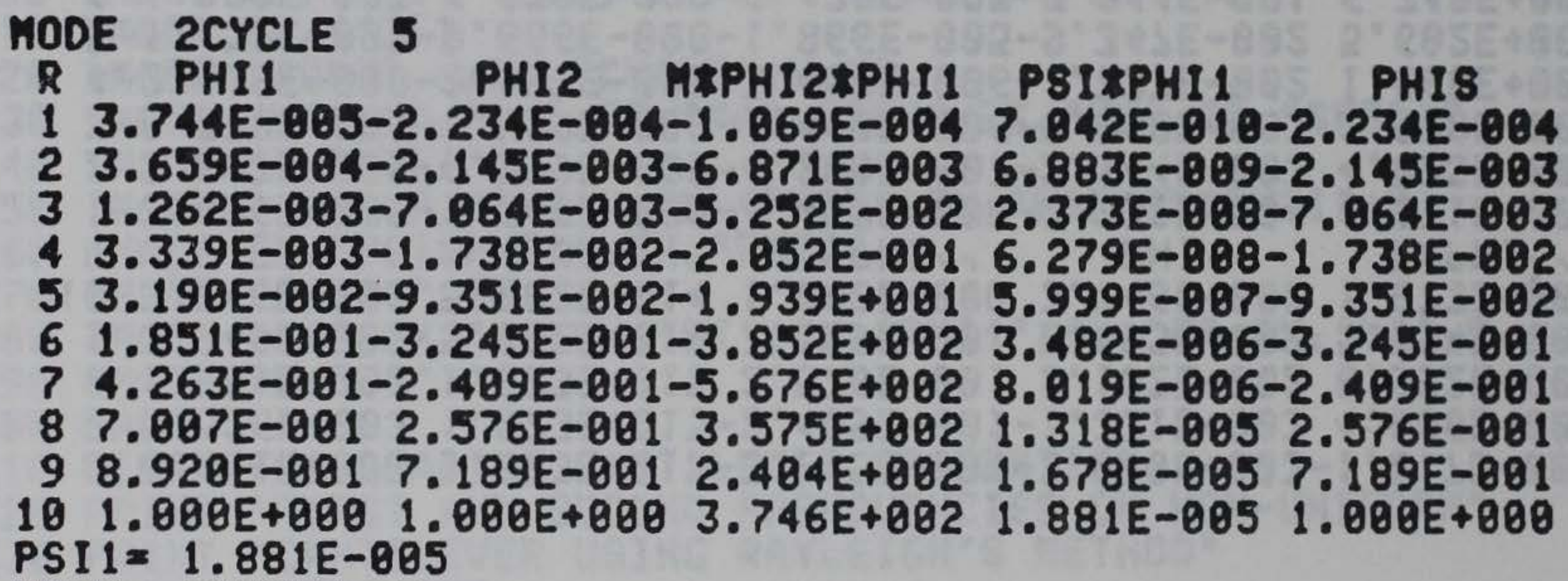
MODE

\begin{tabular}{|c|c|}
\hline 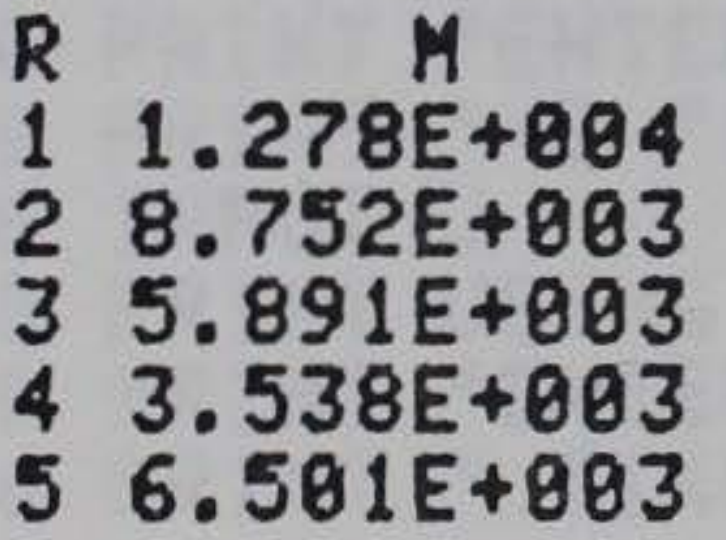 & 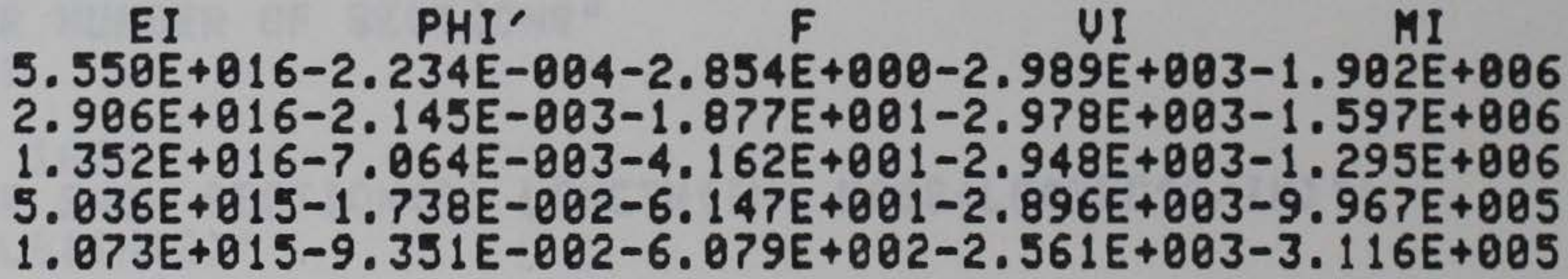 \\
\hline
\end{tabular}


Source Listing for Non-Uniform Cantilever Beam Analysis

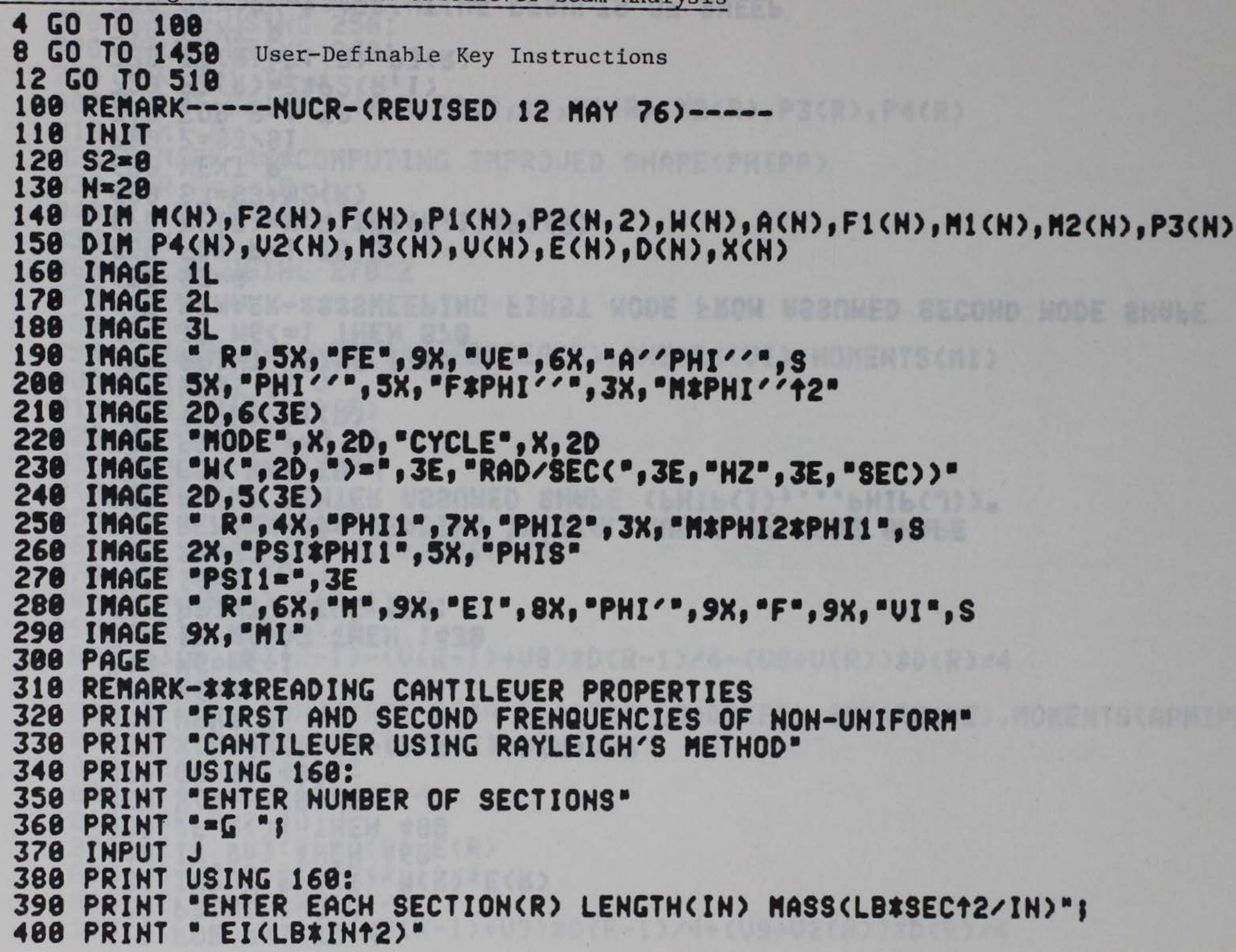




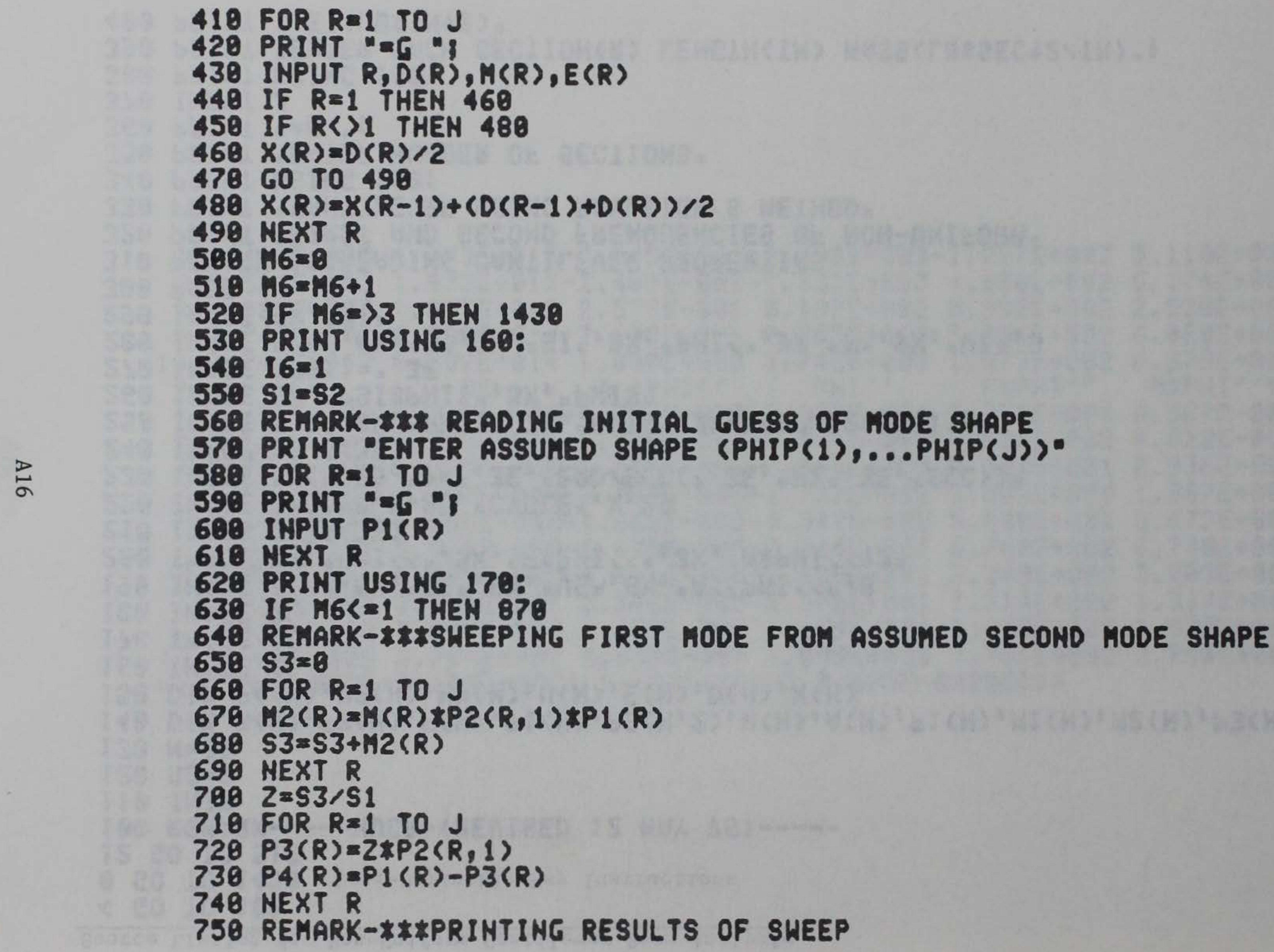




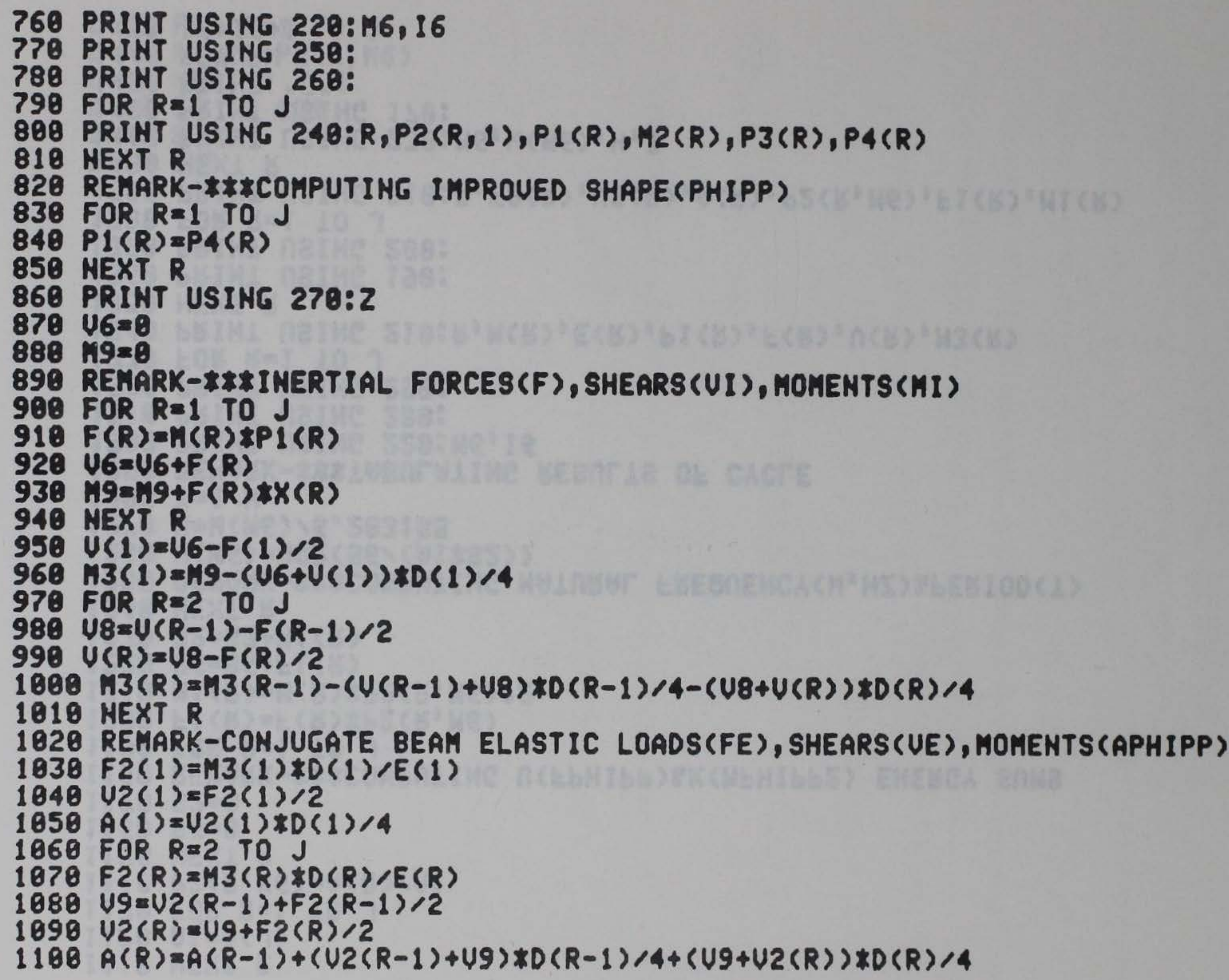




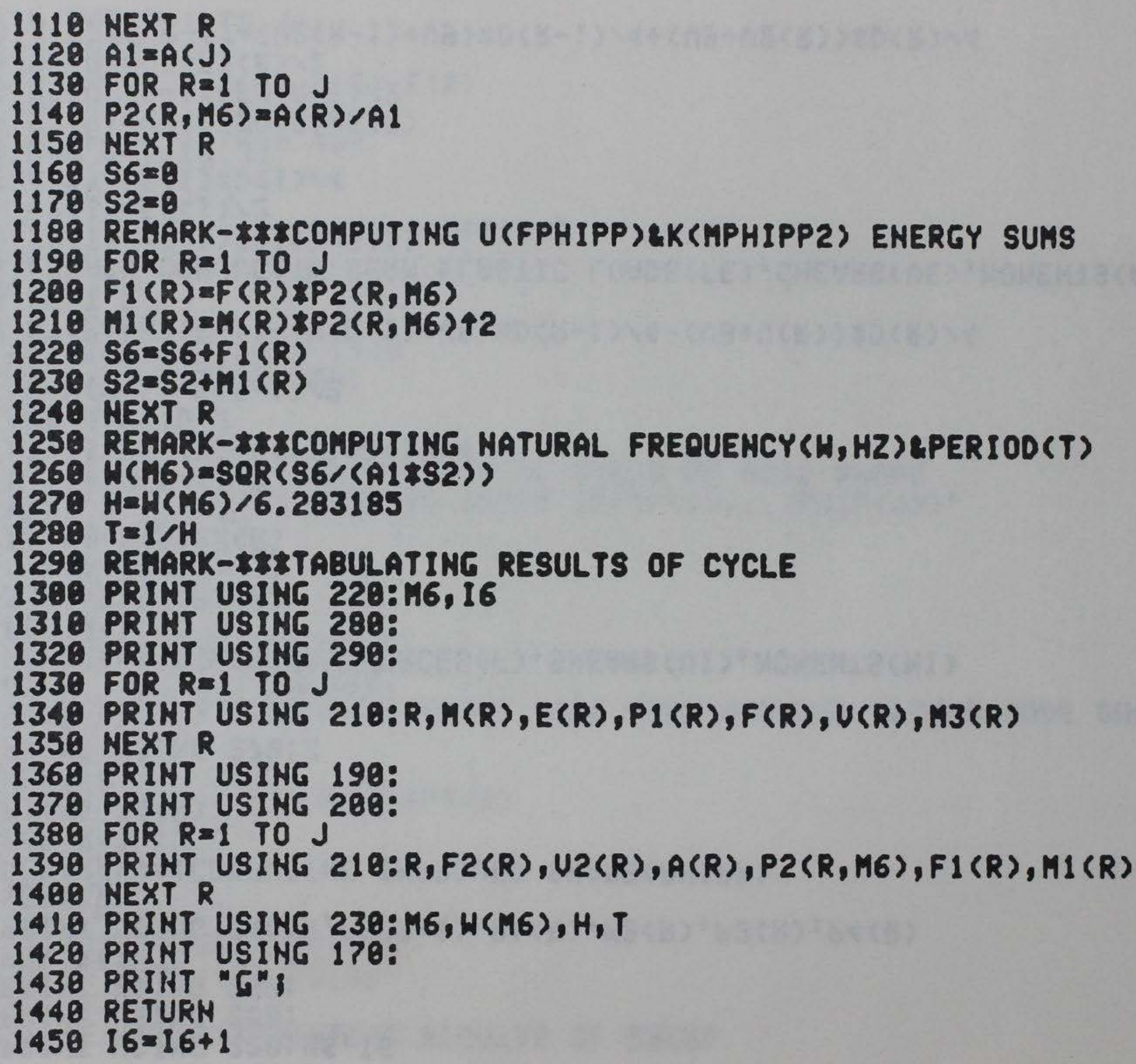




\section{FOR $R=1$ TO J $1478 P 1(R)=P 2(R, M 6)$ \\ 1488 NEXT $R$ \\ 1498 GO TO 630 \\ 1580 STOP \\ 1518 END}


4. Corresponding to the periods

$$
\mathrm{T}_{1}=\frac{1}{\mathrm{f}}=\frac{1}{2.20}=0.454 \mathrm{sec} \quad \mathrm{T}_{2}=\frac{1}{11.26}=0.0888 \mathrm{sec}
$$

the spectral accelerations

$$
\mathrm{Sa}_{1}=0.432 \mathrm{~g} \quad \mathrm{Sa}_{2}=0.216 \mathrm{~g}
$$

were then obtained from Figure $6 \mathrm{~b}$ of the main text.

5. Lateral forces $f_{1}(z)$ acting at the centroid of each segment were then found as follows:

$$
\begin{aligned}
M_{1}= & \sum m(z) \phi_{1}^{2}(z) \\
= & 12,778\left(3.745 \times 10^{-5}\right)^{2}+8752\left(3.66 \times 10^{-4}\right)^{2} \\
& +3537.7\left(3.339 \times 10^{-3}\right)^{2}+6500.5(0.0319)^{2}+6410.7(0.185)^{2} \\
& +5526.4(0.426)^{2}+1980.8(0.7007)^{2}+374.9(0.892)^{2} \\
& +374.6(1)^{2} \\
M_{1}= & 2874.41 \\
L_{1}= & \sum m(z) \phi_{1}(z) \\
= & 5867.48 \\
S_{1}= & 0.432 \mathrm{~g}\left(\frac{386.4 \mathrm{in} . / \mathrm{sec}^{2}}{1 \mathrm{~g}}\right)=166.92 \mathrm{in} . / \mathrm{sec}^{2} \\
& \mathrm{~L}_{1} \mathrm{Sa}_{1} \mathrm{~m}(\mathrm{z}) \phi_{1}(\mathrm{z}) \\
\mathrm{f}_{1}(\mathrm{z})= & \mathrm{M}_{1} \\
\mathrm{~L}_{1} \mathrm{Sa}_{1}= & 340.73 \\
\mathrm{M}_{1} & \\
\mathrm{f}_{1}(51)= & 340.73(12,778)\left(3.745 \times 10^{-5}=163.051 \mathrm{~b}\right. \\
\mathrm{f}_{1}(153)= & 340.73(8752)\left(3.66 \times 10^{-4}\right)=1091.441 \mathrm{~b} \\
\mathrm{f}_{1}(255)= & 340.73(5891.1)\left(1.262 \times 10^{-3}\right)=2533.181 \mathrm{~b} \\
&
\end{aligned}
$$




$$
\begin{aligned}
f_{1}(357) & =340.73(3537.7)\left(3.339 \times 10^{-3}\right)=4024.84 \mathrm{lb} \\
f_{1}(606.36) & =340.73(6500.5)(0.0319)=70,655.95 \mathrm{lb} \\
f_{1}(1003.08) & =340.73(6410.7)(0.185)=404,099.64 \mathrm{lb} \\
f_{1}(1406.22) & =340.73(5526.4)(0.426)=802,164.05 \mathrm{lb} \\
f_{1}(1803) & =340.73(1980.8)(0.7007)=472,916.02 \mathrm{lb} \\
f_{1}(2069.58) & =340.73(374.9)(0.892)=113,944.03 \mathrm{lb} \\
f_{1}(2218.68) & =340.73(374.6)(1)=127,637.721 \mathrm{~b}
\end{aligned}
$$

Lateral forces $f_{2}(z)$ were similarly computed.

$$
\begin{aligned}
& M_{2}=\sum m(z) \phi_{2}^{2}(z) \\
& =12,778\left(-2.232 \times 10^{-4}\right)^{2}+8752\left(-2.144 \times 10^{-3}\right)^{2} \\
& +5891.1\left(-7.06 \times 10^{-3}\right)^{2}+3537.7(-0.01737)^{2} \\
& +6500.5(-0.09347)^{2}+6410.7(-0.3244)^{2}+5526.4(-0.2409)^{2} \\
& +1980.8(0.2576)^{2}+374.9(0.7189)^{2}+374.6(1)^{2} \\
& M_{2}=1753.34 \\
& \mathrm{~L}_{2}=\Sigma \mathrm{m}(\mathrm{z}) \phi_{2}(\mathrm{z})=-2988.83 \\
& \mathrm{Sa}_{2}=0.216 \mathrm{~g}\left(\frac{386.4 \mathrm{in} . / \mathrm{sec}^{2}}{1 \mathrm{~g}}\right)=83.46 \mathrm{in} . / \mathrm{sec}^{2} \\
& f_{2}(z)=\frac{L_{2}}{M_{2}} S a_{2} m(z) \phi_{2}(z) \\
& \frac{\mathrm{L}_{2}}{\mathrm{M}_{2}} \mathrm{Sa}_{2}=-142.27 \\
& f_{2}(51)=(-142.27)(12,778)\left(-2.232 \times 10^{-4}\right)=405.771 b \\
& f_{2}(153)=(-142.27)(8752)\left(-2.144 \times 10^{-3}\right)=2669.67 \mathrm{lb} \\
& f_{2}(255)=(-142.27)(5891.1)\left(-7.06 \times 10^{-3}\right)=5917.351 \mathrm{~b} \\
& f_{2}(357)=(-142.27)(3537.7)(-0.01737)=8742.721 b \\
& \mathrm{f}_{2}(606.36)=(-142.27)(6500.5)(-0.09347)=86,446.01 \mathrm{lb}
\end{aligned}
$$




$$
\begin{aligned}
f_{2}(1003.08) & =(-142.27)(6410.7)(-0.3244)=295,877.70 \mathrm{lb} \\
f_{2}(1406.22) & =(-142.27)(5526.4)(-0.2409)=189,405.49 \mathrm{lb} \\
f_{2}(1803) & =(-142.27)(1980.8)(0.2576)=-75,593.87 \mathrm{lb} \\
f_{2}(2069.58) & =(-142.27)(374.9)(0.7189)=-38,344.00 \mathrm{lb} \\
f_{2}(2218.68) & =(-142.27)(374.61)(1)=-53,294.36 \mathrm{lb}
\end{aligned}
$$

6. Shears $V_{1}(z)$ were then calculated from internal equilibrium.

$$
\begin{aligned}
v_{1}(0)= & 163.05+1091.44+2533.18+4024.84+70,655.95+404,099.64 \\
& +802,164.05+472,916.02+113,944.03+127,637.72 \\
= & 1,999,229.92 \mathrm{lb}
\end{aligned}
$$$$
\mathrm{V}_{1}(102)=1,999,066.87 \mathrm{lb}
$$$$
\mathrm{v}_{1}(204)=1,997,975.43 \mathrm{lb}
$$$$
\mathrm{V}_{1}(306)=1,995,442.25 \mathrm{lb}
$$$$
\mathrm{V}_{1}(408)=1,991,417.41 \mathrm{lb}
$$$$
\mathrm{V}_{1}(804.72)=1,920,761.461 \mathrm{~b}
$$$$
\mathrm{V}_{1}(1201.44)=1,516,661.82 \mathrm{lb}
$$$$
\mathrm{V}_{1}(1611)=714,497.77 \mathrm{lb}
$$$$
\mathrm{v}_{1}(1995)=241,581.75 \mathrm{lb}
$$$$
\mathrm{V}_{1}(2144.16)=127,637.72 \mathrm{lb}
$$$$
\mathrm{V}_{1}(2293.2)=0
$$

Bending moments $M_{1}(z)$ were also computed from equilibrium.

$$
\begin{aligned}
M_{1}(0)= & 163.05(51-0)+1091.44(153-0)+2533.18(255-0) \\
& +4024.84(357-0)+70,655.95(606.36-0) \\
& +404,099.64(1003.08-0)+802,164.05(1406.22-0) \\
& +472,916.02(1803-0)+113,944.03(2069.58-0) \\
& +127,637.72(2218.68-0)=2,950,135,600 \text { in. }-1 b
\end{aligned}
$$




$$
\begin{aligned}
& M_{1}(102)=1091.44(153-102)+2533.18(255-102) \\
& +4024.84(357-102)+70,655.95(606.36-102) \\
& +404,099.64(1003.08-102)+802,164.05(1406.22-102) \\
& +472,916.02(1803-102)+113,944.03(2069.58-102) \\
& +127,637.72(2218.68-102)=2,785,574.064 \text { in. }-1 b \\
& M_{1}(204)=2533.18(255-204)+4024.84(357-204) \\
& +70,655.95(606.36-204)+404,099.64(1003.08-204) \\
& +802,164.05(1406.22-204)+472,916.02(1803-204) \\
& +113,944.03(2069.58-204)+127,637.72(2218.68-204) \\
& =2,542,373,307 \text { in. }-1 b \\
& M_{1}(306)=4024.84(357-306)+70,655.95(606.36-306) \\
& +404,099.64(1003.08-306)+802,164.05(1406.22-306) \\
& +472,916.02(1803-306)+113,944.03(2069.58-306) \\
& +127,637.72(2218-306)=2,338,708,971 \text { in. }-1 b \\
& M_{1}(408)=70,655.95(606.36-408)+404,099.64(1003.08-408) \\
& +802,164.05(1406.22-408)+472,916.02(1803-408) \\
& +113,944.03(2069.58-408)+127,637.72(2218.68-408) \\
& =1,954,598,833 \text { in. }-1 \mathrm{~b}
\end{aligned}
$$$$
M_{1}(804.72)=404,099.64(1003.08-804.72)+802,164.05(1406.22
$$$$
-804.72)+472,916.02(1803-804.72)
$$$$
+113,944.03(2069.58-804.72)
$$$$
+127,637.72(2218.68-804.72)
$$$$
=1,359,359,362 \text { in. }-1 \mathrm{~b}
$$

$M_{1}(1201.44)=802,164.05(1406.22-1201.44)$

$$
+472,916.02(1803-1201.44)
$$




$$
\begin{aligned}
& +113,944.03(2069.58-1201.44)+127,637.72(2218.68 \\
& -1201.44) \\
= & 677,512,080 \mathrm{in} . / 1 \mathrm{~b} \\
M_{1}(1611)= & 472,916.02(1803-1611)+113,944.03(2069.58-1611) \\
& +127,637.72(2218.68-1611) \\
= & 220,615,219 \text { in. }-1 \mathrm{~b} \\
M_{1}(1995)= & 113,944.03(2069.56-1995)+127,637.72(2218.68-1995) \\
= & 37,047,951 \text { in }-1 \mathrm{~b} \\
M_{1}(2144.16)= & 127,637.72(2218.68-2144.16) \\
= & 9,511,563 \text { in. }-1 b \\
M_{1}(2293.2)= & 0 \text { in. }-1 b
\end{aligned}
$$

The shears $V_{2}(z)$ and $M_{2}(z)$ were found similarly.

$$
\begin{aligned}
\mathrm{V}_{2}(0)= & 405.77+2669.67+5917.35+8742.72+86,446.01 \\
& +295,877.70+189,405.49-75,593.87-38,344.00 \\
& -53,294.36 \\
= & 422,232.48 \mathrm{lb} \\
V_{2}(102)= & 421,826.71 \mathrm{lb} \\
V_{2}(204)= & 419,157.04 \mathrm{lb} \\
V_{2}(306)= & 413,239.69 \mathrm{lb} \\
V_{2}(408)= & 404,496.97 \mathrm{lb} \\
V_{2}(804.72)= & 318,050.96 \mathrm{lb} \\
V_{2}(1201.44)= & 22,173,26 \mathrm{lb} \\
V_{2}(1611)= & -167,232.23 \mathrm{lb} \\
V_{2}(1995)= & -91,638.36 \mathrm{lb} \\
V_{2}(2144.16)= & -53,294.4 \mathrm{lb} \\
V_{2}(2293.2)= & 01 \mathrm{~b}
\end{aligned}
$$




$$
\begin{aligned}
& M_{2}(0)=405.77(51-0)+2669.67(153-0)+5917.35(255-0) \\
& +8742.72(357-0)+86,446.01(606.36-0) \\
& +295,877.70(1003.08-0)+189,405.49(1406.22-0) \\
& \text { - } 75,593.87(1803-0)-38,344.00(2069.58-0) \\
& -53,294.36(2218.68-0) \\
& =286,716,569 \text { in } \cdot-1 \mathrm{~b} \\
& M_{2}(102)=2669.67(153-102)+5917.35(255-102)+8742.72(357-102) \\
& +86,446.01(606.36-102)+295,877.7(1003.08-102) \\
& +189,405.49(1406.22-102)-75,593.87(1803-102) \\
& \text { - } 38,344.00(2069.58-192)-53,294.36(2218.68-102) \\
& =243,669,551 \text { in. }-1 \mathrm{~b} \\
& M_{2}(204)=5917.35(255-204)+8742.72(357-204) \\
& +86,446.01(606.36-204)+295,877.7(1003.08-204) \\
& +189,405.49(1406.22-204)-75,593.87(1803-204) \\
& \text { - } 38,344.00(2069.58-204)-53,294.36(2218.68-204) \\
& =200,779,380 \text { in. }-1 \mathrm{~b} \\
& M_{2}(306)=8742.72(357-306)+86,446.01(606.36-306) \\
& +295,877.7(1003.08-306)+189,405.49(1406.22-306) \\
& \text { - } 75,593.87(1803-306)-38,344.00(2069.58-306) \\
& -53,294.36(2218.68-306) \\
& =158,327,146 \text { in } \cdot-1 \mathrm{~b} \\
& M_{2}(408)=86,446.01(606.36-408)+295,877.7(1003.08-408) \\
& +189,405.49(1406.22-408)-75,593.87(1803-408) \\
& \text { - } 38,344.00(2069.58-408)-53,294.36(2218.68-408) \\
& =116,622,576 \text { in. }-1 \mathrm{~b}
\end{aligned}
$$




$$
\begin{aligned}
M_{2}(804.72)= & 295,877.7(1003.08-804.72)+189,405.49(1406.22-804.72) \\
& -75,593.87(1803-804.72)-38,344.00(2069.58-804.72) \\
& -53,294.36(2218.68-804.72) \\
= & -26,702,031 \text { in. }-1 b \\
M_{2}(1201.44)= & 189,405.49(1406.22-1201.44)-75,593.87(1803 \\
& -1201.44)-38,344(2069.58-1201.44)-53,294.36(2218.68 \\
& -1201.44) \\
= & -94,188,907 \text { in. }-1 b
\end{aligned}
$$

$$
\begin{aligned}
M_{2}(1611)= & -75,593.87(1803-1611)-38,344.00(2069.58-1611) \\
& -53,294.36(2218.68-1611) \\
= & -64,483,731 \text { in. }-1 \mathrm{~b}
\end{aligned}
$$$$
M_{2}(1995)=-38,344.00(2069.58-1995)-53,294.36(2218.68-1995)
$$$$
=-14,780,578 \text { in } .-1 b
$$$$
M_{2}(2144.16)=-53,294.36(2218.68-2144.16)
$$$$
=-3,971,496 \text { in. }-1 b
$$$$
M_{2}(2293.2)=0 \text { in. }-1 b
$$

7. Estimates of the probable maximum shears $V(z)$ were then obtained from the root mean square equations.

$$
\begin{aligned}
\mathrm{V}(0) & \doteq \sqrt{(1,999,229.92)^{2}+(422,232.48)^{2}}=2,043,330.71 \mathrm{~b} \\
\mathrm{~V}(102) & =2,043,087.4 \mathrm{lb} \\
\mathrm{V}(204) & =2,041,469.7 \mathrm{lb} \\
\mathrm{V}(306) & =2,037,782.31 \mathrm{~b} \\
\mathrm{~V}(408) & =2,032,082.91 \mathrm{~b} \\
\mathrm{~V}(804.72) & =1,946,915.8 \mathrm{lb} \\
\mathrm{V}(1201.44) & =1,516,823.9 \mathrm{~b}
\end{aligned}
$$




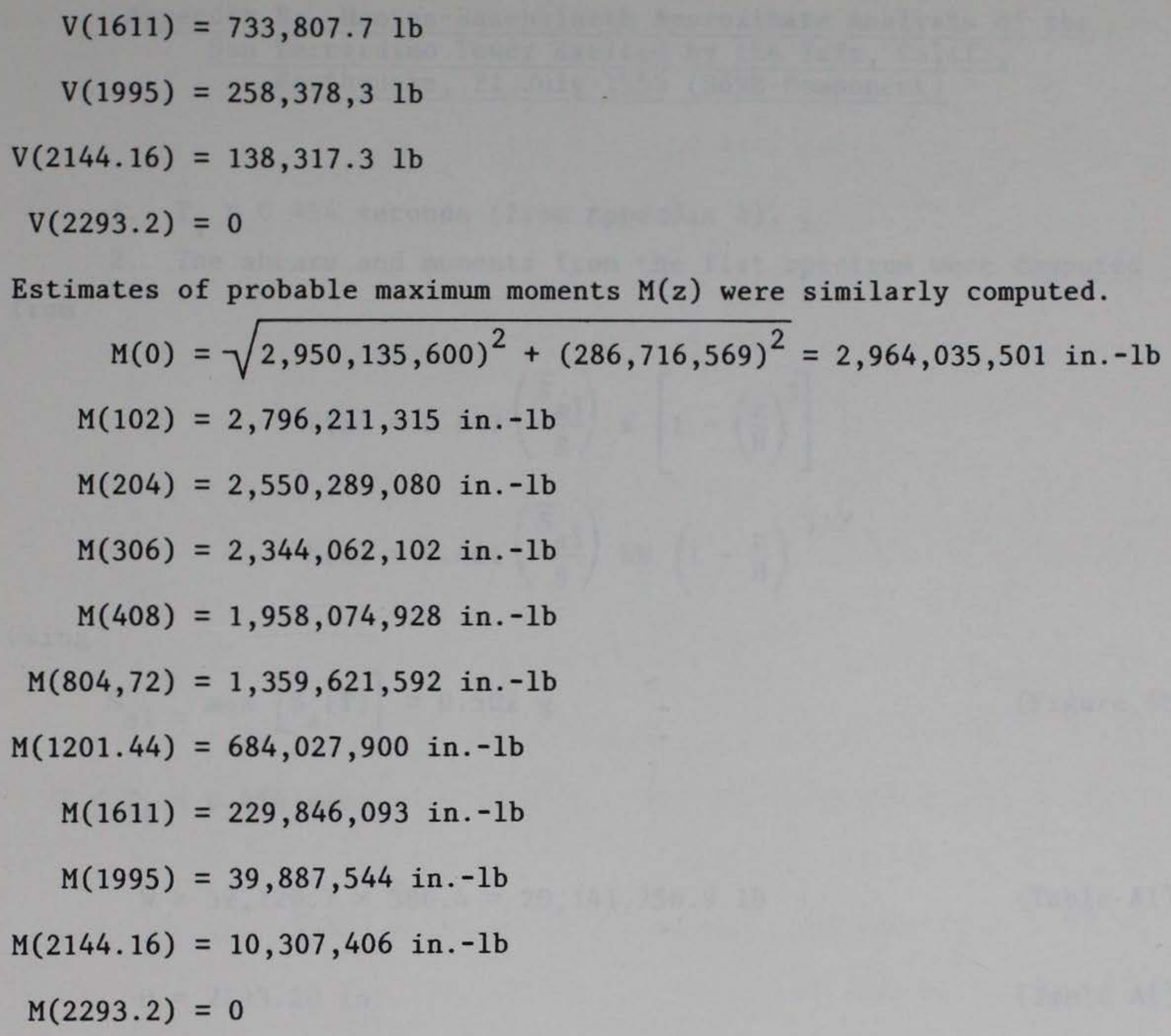




\section{Appendix B: Montes-Rosenblueth Approximate Analysis of the San Bernardino Tower Excited by the Taft, Calif., Earthquake, 21 July 1952 (S69E Component)}

1. $\mathrm{T}_{1}=0.454$ seconds (from Appendix A).

2. The shears and moments from the flat spectrum were computed from

$$
\begin{aligned}
& V(z)=0.647\left(\frac{\widetilde{S}_{a 1}}{g}\right) W\left[1-\left(\frac{z}{H}\right)^{3}\right] \\
& M(z)=0.461\left(\frac{\widetilde{S}_{a 1}}{g}\right) W H\left(1-\frac{z}{H}\right)^{3 / 2}
\end{aligned}
$$

Using

$$
\begin{aligned}
\mathrm{S}_{\mathrm{al}} & =\max \left[\mathrm{S}_{\mathrm{a}}(\mathrm{T})\right]=0.502 \mathrm{~g} \\
\mathrm{~T} \leq \mathrm{T}_{1} & =0.454 \mathrm{sec} \\
\mathrm{W} & =52,126.7 \times 386.4=20,141,756.9 \mathrm{lb} \\
\mathrm{H} & =2293.20 \mathrm{in} .
\end{aligned}
$$

$V(0)=6,541,921.81 \mathrm{~b}$

$\mathrm{V}(102)=6,541,346.1 \mathrm{lb}$

$\mathrm{V}(204)=6,537,316.4 \mathrm{lb}$

$\mathrm{V}(306)=6,526,378.51 \mathrm{~b}$

$V(408)=6,505,078.4 \mathrm{lb}$

$V(804.72)=6,259,229.5 \mathrm{lb}$

$V(1201.44)=5,601,146.71 \mathrm{~b}$

$\mathrm{V}(1611)=4,273,801.01 \mathrm{~b}$

$$
\begin{aligned}
& M(0)=1.0689 \times 10^{10} \text { in. }-1 b \\
& M(102)=9.984 \times 10^{9} \text { in. }-1 b \\
& M(204)=9.295 \times 10^{9} \text { in. }-1 b \\
& M(306)=8.623 \times 10^{9} \text { in. }-1 b \\
& M(408)=7.967 \times 10^{9} \text { in. }-1 b \\
& M(804.72)=5.5898 \times 10^{9} \text { in. }-1 b \\
& M(1201.44)=3.5113 \times 10^{9} \text { in. }-1 b \\
& M(1611)=1.7344 \times 10^{9} \text { in. }-1 b
\end{aligned}
$$


$V(1995)=2,234,590.8 \mathrm{lb}$

$V(2144.16)=1,194,417.81 \mathrm{~b}$

$V(2293.2)=0$
$M(1995)=5.0124 \times 10^{8}$ in. $-1 b$

$M(2144.16)=1.771 \times 10^{8}$ in. $-1 b$

$M(2293.2)=0$

3. The shears and moments from the hyperbolic spectrum were computed from

$$
\begin{gathered}
V(z)=1.553\left(\frac{\widetilde{S}_{\mathrm{al}}}{\mathrm{g}}\right) W\left[\sqrt{1-\left(\frac{\mathrm{z}}{\mathrm{H}}\right)^{2}}-6.25\left(\frac{\mathrm{z}}{\mathrm{H}}\right)^{2}\left(1-\frac{\mathrm{z}}{\mathrm{H}}\right)^{2}\right] \\
M(\mathrm{z})=0.519\left(\frac{\widetilde{S}_{\mathrm{al}}}{\mathrm{g}}\right) \text { WH }\left(1-\frac{\mathrm{z}}{\mathrm{H}}\right)
\end{gathered}
$$

$V(0)=15,702,6341 \mathrm{~b}$

$V(102)=15,509,8181 \mathrm{~b}$

$V(204)=14,995,7561 b$

$V(306)=14,249,975 \mathrm{lb}$

$V(408)=13,352,859 \mathrm{lb}$

$V(804.72)=9,612,3851 \mathrm{~b}$

$V(1201.44)=7,269,2381 b$

$V(1611)=6,888,6611 \mathrm{~b}$

$V(1995)=6,487,236 \mathrm{lb}$

$V(2144.16)=5,206,1641 \mathrm{~b}$

$V(2293.2)=0$

$$
\begin{aligned}
& M(0)=1.2034 \times 10^{10} \text { in. }-1 b \\
& M(102)=1.1499 \times 10^{10} \text { in. }-1 b \\
& M(204)=1.0963 \times 10^{10} \text { in. }-1 b \\
& M(306)=1.0428 \times 10^{10} \text { in. }-1 b \\
& M(408)=9.893 \times 10^{9} \text { in. }-1 b \\
& M(804.72)=7.811 \times 10^{9} \text { in. }-1 b \\
& M(1201.44)=5.729 \times 10^{9} \text { in. }-1 b \\
& M(1611)=3.580 \times 19^{9} \text { in. }-1 b \\
& M(1995)=1.5649 \times 10^{9} \text { in. }-1 b \\
& M(2144.16)=7.8212 \times 10^{8} \text { in. }-1 b \\
& M(2293.2)=0
\end{aligned}
$$

4. The shears and moments from the flat spectrum should be used since they are smaller in every instance than those from the hyperbolic spectrum. 